\title{
La geografia a la Universitat Autònoma de Barcelona: un projecte d'Enric Lluch (I)*
}

\author{
Antoni F. Tulla Pujol \\ Maria Dolors Garcia Ramon \\ Helena Estalella Boadella \\ Universitat Autònoma de Barcelona. Departament de Geografia \\ antoni.tulla@uab.cat \\ mariadolors.garcia.gamon@uab.cat \\ helena.estalella@uab.cat
}

\section{Resum}

S'ha complert mig segle d'ensenyament de la geografia a la UAB (de 1969 a 2019). Al present article se n'hi expliquen els primers vint anys, fins a completar el desenvolupament de la Llei de reforma universitària (LRU) a la nostra universitat, i s'hi dona a conèixer quin era l'equip acadèmic que va acompanyar Enric Lluch (1928-2012) en aquesta experiència. S'hi introdueix la geografia que recollia els enfocaments innovadors que arribaven principalment de França, dels països anglosaxons i d'Itàlia. També s'hi detallen els plans d'estudi en què es basava la impartició de la geografia a la Facultat de Filosofia i Lletres, els seminaris formatius i les primeres recerques. El relat s'ha iniciat amb les experiències personals i acadèmiques de dues professores i un professor que varen formar part de l'equip inicial, per després comentar els principals trets del Departament, des de la governança fins a la consolidació de la geografia a la UAB com una disciplina acadèmica i com una forma d'entendre la societat i el territori. Constitueix una oportunitat per poder explicar l'etapa fundacional com un període històric significatiu per al desenvolupament posterior del Departament de Geografia.

Paraules clau: Documents d'Anàlisi Geogràfica; Enric Lluch; geografia a la Universitat Autònoma de Barcelona; governança; innovació docent

* Amb aquest article volem retre homenatge al professor Enric Lluch i Martín (1928-2012), introductor de la geografia a la UAB. El text és la primera part d'una contribució més extensa que vol commemorar el cinquantè aniversari del Departament de Geografia de la UAB. La segona part de la contribució serà publicada l'any 2020. Aquesta primera part recorda la configuració del grup humà que ha constituït el nucli històric del Departament i la seva dedicació docent. La segona part recollirà uns altres elements de l'impacte científic i acadèmic del Departament. Al final d'aquesta contribució especial hi ha annexos amb diferents taules que ajuden a entendre aquest procés. 
Resumen. La geografía en la Universidad Autónoma de Barcelona: un proyecto de Enric Lluch (I)

Se ha cumplido medio siglo de enseñanza de la geografía en la UAB (de 1969 a 2019). En el presente artículo se cuentan los primeros veinte años, hasta completar el desarrollo de la Ley de Reforma Universitaria (LRU) en nuestra universidad, y se da a conocer cuál era el equipo académico que acompañó a Enric Lluch (1928-2012) en esta experiencia. Se introduce la geografía que recogía los enfoques innovadores que llegaban principalmente de Francia, de los países anglosajones y de Italia. También se detallan los planes de estudio en los cuales se basaba la impartición de la geografía en la Facultad de Filosofía y Letras, los seminarios formativos y las primeras investigaciones. El relato se ha iniciado con las experiencias personales y académicas de dos profesoras y un profesor que formaron parte del equipo inicial, para luego comentar los principales rasgos del Departamento, desde la gobernanza hasta la consolidación de la geografía en la UAB como disciplina académica y como una forma de entender la sociedad y el territorio. Constituye una oportunidad para poder explicar la etapa fundacional como un período histórico significativo para el desarrollo posterior del Departamento de Geografía.

Palabras clave: Documents d'Anàlisi Geogràfica; Enric Lluch; geografía en la Universitat Autònoma de Barcelona; gobernanza; innovación docente

\section{Résumé. La géographie à l'Universitat Autònoma de Barcelona : un projet d'Enric Lluch (I)}

Cinquante ans d'enseignement de la Géographie à l'UAB (1969 à 2019) viennent d'être célébrés. Les 20 premières années sont présentées, jusqu'à l'achèvement du développement de la loi sur la réforme de l'université (LRU) à l'UAB, ainsi que l'équipe académique qui a accompagné Enric Lluch (1928-2012) dans cette expérience. On a introduit la géographie qui a rassemblé les approches novatrices venues principalement de la France, des pays anglo-saxons et de l'Italie. Les plans d'études dans lesquels la géographie est enseignée à la Faculté de Philosophie et Lettres, les séminaires de formation et les premières enquêtes sont également expliqués. L'histoire a commencé par l'expérience personnelle et académique de trois enseignants (deux femmes et un homme) faisant partie de l'équipe initiale, pour ensuite présenter les principales caractéristiques du département, de la gouvernance à la consolidation de la géographie à l'UAB, en tant que discipline universitaire et comme moyen de comprendre la société et le territoire. C'est l'occasion d'expliquer le stade fondamental comme une période historique importante pour le développement ultérieur du Département de Géographie.

Mots-clés: Documents d'Anàlisi Geogràfica; Enric Lluch; Géographie à l'Universitat Autònoma de Barcelona; gouvernance; innovation de l'enseignement

\section{Abstract. Geography at the Universitat Autònoma de Barcelona: A project of Enric Lluch (I)}

Geography has been taught at the Autonomous University of Barcelona (UAB) for 50 years (1969-2019). This paper explores the first 20 years of geography until the entry into force of the University Reform Law (LRU) at the UAB and the academic team that accompanied Enric Lluch (1928-2012) in this experience. The introduction of geography based on innovative approaches coming mainly from France, English-speaking countries and Italy is discussed. The programs of study in which geography is taught at the Faculty of Philosophy and Letters, the training seminars and the first investigations are also described. The story begins with the personal and academic experiences of two female teachers and a male teacher who formed part of the initial team, and then focuses on the main features of the 
department, from governance to the consolidation of geography at the UAB as an academic discipline and as a way of understanding society and the territory. It is an opportunity to explain the foundational stage as a significant historical period for the subsequent creation of the Geography Department at the Universitat Autònoma de Barcelona.

Keywords: Documents d'Anàlisi Geogràfica; Enric Lluch; geography; Universitat Autònoma de Barcelona; governance; teaching innovation

\section{Sumari}

1. Introducció. Estructura de l'article

2. El posicionament personal: Maria Dolors Garcia Ramon, Helena Estalella Boadella i Antoni F. Tulla Pujol

3. La lluita política per una universitat pública catalana i democràtica

4. Els plans d'estudis de la geografia a la UAB
5. El capital humà del Departament de Geografia

6. Governança del Departament de Geografia

7. Reflexions finals (I)

Referències bibliogràfiques

Annexos

\section{Introducció. Estructura de l'article}

Ara fa cinquanta anys que s'imparteix docència de geografia a la Universitat Autònoma de Barcelona (UAB) i ens ha semblat oportú poder explicar quin tipus de disciplina s'hi ensenyava al començament i qui la hi va iniciar. El període que tractarem és el comprès entre els cursos 1969-1970 i 1989-1990, des del primer professor de geografia, Enric Lluch i Martín (1928-2012), fins que es va completar el desplegament de la Llei de reforma universitària (LRU) ${ }^{1}$ a la UAB, amb el Decret de departaments de la LRU (12-12-1984), que demanava un mínim de dotze professors de plantilla permanent. El mes de maig de 1985, la Junta de Govern de la UAB va decidir que les àrees de coneixement no es podien partir i es varen crear departaments intercentres. El Claustre de la UAB de desembre de 1986 va establir el Pla Nadal (19871991), mitjançant el qual es creaven places de titular d'escola universitària (TEU) interines per al professorat amb un mínim de tres anys de contracte a la UAB i que es comprometessin a dipositar-hi la tesi doctoral en un termini de dos a tres anys. Un cop defensada, podien concursar llavors a places de titular d'universitat (TU). Cal dir que en el curs 1991-1992 hi va haver una nova reforma profunda de plans d'estudi i que en el curs 1992-1993 es va encetar un esclat de noves universitats territorials a Catalunya (UdG, UdL i URV).

La UAB, creada l'any 1968 (Riquer i Molinero, 2018), va representar un nou enfocament acadèmic de la docència $i$ de la recerca universitàries, basades en les noves tendències científiques a Europa i a l'Amèrica del Nord. En

1. Ley Orgánica 11/1983, de 25 de agosto, de reforma universitaria. 
la seva fundació va haver-hi la voluntat d'establir quatre principis d'autonomia universitària: lliure contractació del personal docent, lliure admissió de l'alumnat —amb numerus clausus_, lliure redacció dels plans d'estudi i lliure administració dels recursos econòmics de què disposés. Una part dels nous acadèmics, a centres com ara Lletres, provenien del professorat expulsat de la Universitat de Barcelona (UB) per l'assistència a la Caputxinada (Colomer, 1978; Fernández Buey, 2009) en l'acte de constitució del SDEUB². Enric Lluch i Martín, professor de geografia a la UB, en aquell moment va ser un d'aquests casos. L'expulsió li va donar l'oportunitat d'iniciar l'organització de la llicenciatura de Geografia a la UAB. La seva concepció d'aquesta disciplina contemplava els lligams que s'establien entre el territori i la societat, cercant un compromís entre els professionals i la societat civil.

Mitjançant aquest article ens sembla important deixar constància del projecte de la nova geografia que va endegar Enric Lluch l'any 1969 a la UAB. A partir de dos articles que es publicaran consecutivament en el DAG, volem fer memòria del naixement del Departament, el desenvolupament de la docència i la recerca, a més de transmetre modestament el seu llegat a les generacions futures. No pretenem fer una anàlisi de la seva obra escrita, treball publicat a cura del seu deixeble Abel Albet (2007), sinó presentar els grans temes desenvolupats a l'entorn de la fundació de la geografia a la UAB. L'estructura de l'article comença amb un breu posicionament de les autores i de l'autor, que expliquen els motius de formar part del projecte d'Enric Lluch. A continuació s'hi expliquen els tres plans d'estudi en què va participar la geografia a la UAB, l'equip humà que hi treballava i la governança del Departament. En el segon article ens aproparem a les jornades de formació i preparació de la docència, que ajuden a comprendre aquest esforç col-lectiu, i presentarem la creació i el desenvolupament del $\mathrm{DAG}^{3}$, a més dels principals projectes de recerca que va promoure l'Enric, primer, i el professorat que l'acompanyava, després.

La metodologia emprada s'ha fonamentat en les vivències i el material de les persones autores, aportada i discutida en grup, juntament amb un treball de recerca sobre els arxius del Departament i una part de la documentació lliurada per Montserrat Galera ${ }^{4}$ del material administratiu i didàctic d'Enric Lluch. S'ha completat amb el material bibliogràfic i d'estudi disponible 5 .

2. Sindicat d'Estudiants de la Universitat de Barcelona.

3. Documents d'Anàlisi Geogràfica, revista del Departament de Geografia de la UAB i també de la UdG des de l'any 1994.

4. Cessió del material didàctic, de recerca i d'ús administratiu d'Enric Lluch i Martín a la Biblioteca d'Humanitats l'any 2014. L'està ordenant i classificant la professora Pilar Riera.

5. Volíem agrair a Montserrat Izquierdo i a Joan Pie, de la secretaria, que hagin buscat alguns documents en els arxius del Departament, a les companyes de Girona, Montserrat Terradas i Isabel Salamaña, i de Bellaterra, Rosa Ascon i Pilar Riera, així com a Pau Alegre, que ens hagin facilitat documentació i ens hagin fet alguns aclariments. També a Joan Manuel Soriano la correcció lingüística. 


\section{El posicionament personal: Maria Dolors Garcia Ramon, Helena Estalella Boadella i Antoni F. Tulla Pujol ${ }^{6}$}

La manera com vam conèixer Enric Lluch és una forma d'explicar la participació de cadascuna de nosaltres en el projecte col-lectiu d'iniciar la geografia a la UAB liderat per ell. Vàrem ser les tres primeres persones contractades, l'octubre de 1969 i de 1970.

M. Dolors Garcia Ramon va tenir Enric Lluch de professor de l'assignatura de Geografia d'Espanya a la UB durant el curs 1964-1965. Aquest fet va ser decisiu per decantar-se a estudiar Geografia en lloc d'Antropologia. Uns quants anys després va fer un màster de Geografia a la Universitat de California a Berkeley (EUA), on va conèixer Carl Sauer (1956). L'any 1969, Enric Lluch li va oferir una ajudantia a la recentment creada UAB, encàrrec que també li van oferir a la UB. El primer any va compaginar les dues feines, però el segon va haver de triar i, sense dubtar-ho gens, es va decantar per la UAB. Els nous ensenyaments de geografia que s'encetaven eren molt atraients $i$ innovadors, en la línia que havia vist en la seva estada a la universitat americana, experiència que Enric Lluch sempre li va valorar en gran manera ${ }^{7}$. En aquells moments la geografia catalana i l'espanyola eren, en general, molt tradicionals, però el projecte de la UAB apareixia com a clarament renovador, ben engrescador acadèmicament, tant des del punt de vista de la docència com de la recerca. Però, a més, la Maria Dolors explica que amb l'Enric va aprendre a fer classes i a gaudir-ne. L'any 1975 va realitzar una estada de postgrau d'un any a l'Escola Graduada de Geografia de la Universitat Clark (EUA), on va conèixer geògrafs crítics com ara Richard Peet (1977) o Anne Buttimer, i també va rebre aportacions de geògrafes americanes com ara Janice Monk i Susan Hanson (1982), entre d'altres, la qual cosa li va permetre seguir els nous corrents de manera molt propera.

Els ensenyaments de geografia tenien lloc al Departament de Ciències Socials, de la Facultat de Lletres (a Sant Cugat). La concepció d'aquest departament era molt imaginativa i feia que hom s'hi sentís molt a gust. A l'Autònoma l'ambient era molt especial durant els primers anys. Semblava que era possible ignorar els motlles de les normatives ministerials i que qualsevol bona idea es podia dur a la pràctica, i en bona mesura era així. A la llarga no seria ben bé d'aquesta manera, però aquell ambient estimulava l'esperit innovador en una disciplina, la geografia, encara poc institucionalitzada a Espanya, i l'Enric ho va saber fer molt bé. La Maria Dolors creu que l'èmfasi que es va donar a l'ensenyament per sobre de la recerca va permetre que fóssim un departament modèlic, tant en el desenvolupament dels plans d'estudi com en el contingut i l'aplicació dels plans docents i en l'organització activa i molt participativa de tots els nous professors i professores que hi van anar arribant. Cal dir que

6. Apartat basat en els escrits personals de cadascuna de les persones autores i ajustat per a aquest article.

7. La Maria Dolors recorda que li va demanar que li ensenyés les pràctiques i tots els materials inclosos en els exàmens que havia fet servir a Berkeley, que els considerava molt interessants. 
aquest ambient tan estimulant només va ser possible per la dedicació i l'entusiasme del seu fundador i inspirador.

Helena Estalella va conèixer primer el nom d'Enric Lluch que no pas la persona. Ella era alumna de la UB, on començava el segon curs, i formava part dels universitaris que constituïen el clandestí — aleshores tot era clandestíSDEUB. A segon s'hi aprenia la geografia d'Espanya i el professor que havien de tenir l'havien expedientat i expulsat de la Universitat. Com a protesta, els estudiants es varen negar a entrar a l'aula on el nou ensenyant, un catedràtic, els havia de fer les classes. El professor expulsat era Enric Lluch. Llavors va ser natural que quan li va proposar a l'Helena d'anar a treballar a l'Autònoma, un cop acabats els darrers exàmens de la carrera, ella li digués que sí, encara que en aquells temps allò que es considerava políticament correcte era dedicar-se a l'educació secundària per transformar la societat a través de l'ensenyament, tal com van fer molts dels seus amics. La qüestió, però, tal com explica l'Helena, era com es podia dir que no a Enric Lluch, que aleshores era tot un símbol. Al llarg dels anys, per a l'Helena, l'Enric mai no va perdre el significat d'aquells dies. Era la persona que sabia on era el nord ètic i polític per complexa que fos la situació, era la persona que tothom respectava, els joves i els no tan joves. L'Enric no va ser únicament el nord ètic dins la lluita política universitària, sinó també el nord científic i disciplinari dins la geografia i el nord del grup de geògrafs de l'Autònoma. Aquells primers anys van ser els de l'entusiasme. L'Helena recorda que sempre es volia anar més enllà del que era possible, sempre s'imaginava un futur que se sabia que havia d'arribar.

El primer nom que va tenir el grup de geògrafs de l'Autònoma ens el van posar des de fora. Ens dèiem L'Enric i les seves Noies, o Les Lluch's Girls. Al primer curs l'Enric hi va entrar acompanyat de la Maria Dolors, i no era l'única professora de la Facultat. L'any següent hi va entrar l'Helena, una altra dona, i això era ben estrany en aquells temps. Al llarg dels anys següents, tot i que hi van començar a treballar homes com ara Jordi Borja i Antoni F. Tulla, també en van continuar formant part dones: Laura Zumin, Rosa Ascon, Pilar Riera i Pilar Benejam. No hi havia cap altre grup disciplinari amb tanta presència femenina. Es més, a molts no n'hi havia gens. D’aquí ve el nom, que podria considerar-se pejoratiu. L'Enric havia treballat abans amb mestres, creia en la igualtat de gènere i la practicava. La primera denominació que ens vam posar nosaltres mateixos dins del Departament de Ciències Socials va ser el de Divisió de Geografia. Aleshores els sociòlegs, alguns historiadors i els geògrafs estàvem junts a Lletres i compartíem un únic despatx amb quatre o cinc taules. No va ser fins un temps després que ens vàrem poder constituir com a departament. Ja abans del primer nom, el de Divisió, sabíem qui érem i quina geografia volíem impartir.

En aquells moments hi havia poques assignatures de geografia. Estaven als cursos comuns de la llicenciatura de Filosofia i Lletres: la Geografia General a primer i la Geografia d'Espanya a segon. Les assignatures eren sempre compartides i el pla d'estudis se seguia de manera conjunta amb llibres sobre la taula. Anàvem a casa de l'Enric, on ens ensenyava les obres essencials sobre 
l'assignatura, ens les explicava, ens demanava l'opinió sobre si els posàvem a la bibliografia i aleshores es parlava de com podíem preparar el programa. Eren reunions aterridores. Des de la ignorància de molts de nosaltres se'ns obrien mons nous cada cinc minuts. Autors com ara Pau Vila (1926), Lluís Solé Sabarís (1964) o Jaume Vicens Vives $(1950,1954)$ varen ser un descobriment per a la major part de les persones que hi assistíem. Tot el professorat jove ens passàvem molt de temps, jo diria que gairebé tot el que teníem, estudiant llibres per poder fer classes. Els nostres alumnes tenien en un mateix semestre professors de la vàlua acadèmica de Jordi Nadal i Oller, el mateix Lluch, en Gabriel Ferreter i a nosaltres, joves i inexperts com a docents.

L'Enric sostenia, i nosaltres darrere seu, que la geografia era una ciència social allunyada de la geografia regional francesa, que era la imperant a la resta de departaments de geografia de l'Estat. La seva mirada anava sempre cap a l'exterior. Volia veure què es feia a Anglaterra, què es feia als EUA, què es feia de nou a França o a Itàlia, i també a Espanya, però molt menys. Des del començament, en el contingut d'una assignatura, a part de la teoria, hi havia una part pràctica, i a més el que aleshores en dèiem "excursions» i ara se'n diu "treball de camp». Les pràctiques estaven conformades per petits treballs col-lectius de recerca en què s'aplicaven els coneixements teòrics, com ara la pràctica d'usos del sòl periurbà a la ciutat de Girona el curs $1969-1970^{8}$ o be l'aplicació del model de Román Perpiná Grau (1954) sobre la distribució de la població a Espanya amb les dades del darrer cens quan treballàvem a Sant Cugat. L'Enric pensava que la recerca també l'havien de fer els universitaris des del començament dels seus estudis. En aquells primers anys les poques assignatures que hi havia de geografia a la llicenciatura de Filosofia i Lletres servien per experimentar continguts, més ben dit, eren l'eix vertebrador de la feina col.lectiva basada en el respecte i la confiança que l'Enric ens tenia i en el treball aferrissat i la dedicació que representava per a nosaltres.

Antoni F. Tulla va seguir un camí diferent, potser com un cas de les persones que varen col-laborar amb l'Enric des d'un origen disciplinari més allunyat de la geografia. Els primers contactes amb l'Enric i la geografia a la UAB varen ser com a ajudant de Sociologia del professor Juli Busquets i Bragulat l'octubre de 1970. Els primers anys (1969-1972) el professorat de Geografia, Història del Pensament Polític i Sociologia formaven part del Departament de Ciències Socials, encapçalats per Enric Lluch, Antoni Jutglar i Juli Busquets, respectivament. Durant els cursos 1970-1971 i 1971-1972 Antoni F. Tulla va compaginar el treball d'economista en el Servei d'Estudis del Banco Urquijo de Barcelona amb la docència de sociologia, $\mathrm{i}$ hi va realitzar tres col-laboracions que el varen atraure cap a la geografia:

a) Un estudi de sociologia rural amb els alumnes sobre cooperatives i societats agràries de transformació (SAT) ramadera de l'Alt Urgell (Tulla, 1973).

8. Professorat que la va impartir el curs 1969-1970: M. Dolors Garcia Ramon, Enric Lluch i Montserrat Moli. 
b) Un seminari de geografia urbana preparant una enquesta i una visita al barri del Turó de la Peira durant el curs que impartia la professora Rosa Ascon.

c) L'assistència a les sortides de camp al delta de l'Ebre, Tortosa, Tarragona $\mathrm{i}$ el Baix Camp, organitzades pels professors Enric Lluch, Helena Estalella i Maria Dolors Garcia Ramon.

La participació en cursos de formació i en jornades d'estudi preparades pels geògrafs varen ser molt enriquidores, en especial el mes de juny de 1972, quan es va fer un debat molt profund sobre la geografia com a ciència social, amb l'objectiu de millorar-ne la docència i la recerca. L'interès d'Enric Lluch pels nous enfocaments de la geografia anglosaxona va comportar que oferís a Antoni F. Tulla la possibilitat d'anar a estudiar a Anglaterra aprofitant una beca del Patronat de la UAB ${ }^{9}$. Això li va permetre romandre al Departament de Geografia de la Universitat de Bristol durant dos anys, un dels llocs emblemàtics de la geografia teorètica i quantitativa, i treballar conjuntament amb Peter Haggett (Haggett, 1965; Haggett et al., 1977) i també amb David Harvey (1969, 1973), qui va fer el balanç de la geografia teorètica i va iniciar els plantejaments de la geografia crítica. Michael Chisholm (1962, 1965), especialista en geografia rural, va ser el seu supervisor, encara que Nigel Thrift (1983) i John R. Short (1989) eren els postgraduats que varen ajudar-lo a integrar-se en la vida social i acadèmica del Departament. El primer va transformar-se des de la modelística de l'espaitemps fins a l'anàlisi marxista en geografia i va ser l'introductor del concepte soft capitalisme. El segon sempre va mostrar una visió crítica de la ciutat i va ser dels primers geògrafs anglosaxons interessats per les aportacions d'Henri Lefebvre (1968) i Manuel Castells (1972), textos treballats en els seminaris a Bristol amb John Short, Keith Bassett, Tarik Okyay i Antoni F. Tulla. Els coneixements que tenia d'economia i de matemàtiques varen ajudar-lo en aquest nou enfocament de la geografia, i en tornar a la UAB els va poder utilitzar en la docència i la recerca en el si del Departament. En la seva tesi de doctorat (Tulla, 1982, 1993) hi va incloure metodologia quantitativa com a conseqüència de l'estada a Bristol, però també l'anàlisi de la transformació de l'agricultura en el capitalisme des d'un enfocament marxista.

L'atracció que Antoni F. Tulla va sentir per la geografia es fonamentava en la seva visió global dels problemes. Probablement en la mateixa sintonia que Pierre Vilar (1962) en el seu enfocament de la història, tal com va aprendre de Jordi Nadal i Oller com a alumne seu a Història Econòmica. Considerar el territori com un producte social (Estalella i Tulla, 1978) resumia el paradigma de la geografia en el marc de les ciències socials renovades al maig de 1968. Dos autors, Gilles Postel-Vinay (1974) i Alain Lipietz (1977), varen ser cabdals en l'orientació de la docència i la recerca d'Estalella i Tulla. La influència que la geografia radical americana va exercir en M. Dolors Garcia Ramon (1978) la va portar a investigar la formació del paisatge anarquista en el camp de la Franja

9. Durant uns deu anys, la UAB disposava de recursos de la societat civil i de l'Administració local per a la formació del professorat, incloses beques per fer estades a l'estranger. 
d'Aragó, treball que va presentar el 1978 en el Col-loqui de l'AGE a Granada. En conjunt, es podia concloure que l'escala territorial com a mètode d'anàlisi, des de la realitat local fins als grans problemes del món, permetia tractar la realitat en diversos nivells de complexitat. L'anàlisi local, en el Departament, estava estretament vinculada al treball de camp i al contacte directe amb les persones i les realitats. Aquesta orientació es va transmetre als alumnes i als professors joves, que l'any 1988 varen crear l'Associació de Geògrafs Professionals de Catalunya (AGPC), embrió del futur Col-legi de Geògrafs, per promoure i defensar els interessos de les sortides professionals dels estudis de geografia (Busquets et al., 2015).

En aquells anys es valorava molt la "teoria i la praxi» com dues vessants inseparables del coneixement. El grup de geògrafes i geògrafs que treballaven amb Enric Lluch estudiaven i experimentaven sobre els nous conceptes de la geografia francesa (Beaujeau-Garnier i Chabot, 1963; Lacoste, 1965; Claval, 1968; Kayser, 1972; Garnier, 1973; Gourou, 1973; Derruau, 1976; Bret et al., 1977; Dollfus, 1978; Lebeau, 1979), italiana (Demmatteis, 1970, 2002; Gambi, 1973; Quaini, 1975, 1978) i anglosaxona (Isard, 1960; Brookfield, 1975; Massey i Meegan, 1982), i això esperonava l'interès per innovar en la docència $i$, en el cas de les autores i l'autor, en la investigació sobre la geografia rural. Hi predominaven les aproximacions epistemològiques culturals, socials, econòmiques $\mathrm{i}$ teorètiques, amb una introducció als enfocaments de gènere $\mathrm{i}$ als mètodes quantitatius. L'anàlisi marxista i la història global constituïen la referència que ho englobava tot. En aquest sentit, convé recordar les aportacions del professorat del Departament, com ara les de M. Dolors Garcia Ramon en metodologia qualitativa i quantitativa (Garcia Ramon, 1981) i pensament geogràfic (Garcia Ramon, 1985); les d'Antoni F. Tulla (1982, 1993), que plantejava la possibilitat de combinar la geografia marxista amb la quantitativa; les d'Helena Estalella (1982) i Pilar Riera (1988), que empraven els conceptes i la metodologia de la teoria del lloc central, i les de Pau Alegre (1988), que realitzava una reflexió teòrica dels models territorials principals.

El treball conjunt era molt motivador. S'organitzaven multitud de reunions perquè es parlava i es discutia de quasi tot, encara que amb una clara direcció del professor Enric Lluch. El que en quedava era la col-laboració que s'establia entre els diversos membres, que s'agrupaven per equips o de manera col-lectiva. La direcció de l'Enric es basava en el que succeïa en altres països $i$ en altres disciplines, però també tenia el que avui anomenaríem un "full de ruta" ben definit per tirar endavant el projecte de la geografia que s'impartia des de la UAB.

\section{La lluita política per una universitat pública catalana i democràtica}

Enric Lluch i l'ensenyament de la geografia varen començar el 1969 a la UAB, mentre que el dictador no es va morir fins al novembre de 1975. Durant aquest període es van viure anys de lluita política contra el règim, un nombre important del professorat militava clandestinament en partits polítics d'esquerres 
i els que no en formaven part provenien de les lluites estudiantils. Aquesta situació era l'habitual a la nostra universitat i en nosaltres mateixos. Teníem policies - la «secreta» — a les nostres classes per vigilar el que hi dèiem. El degà de la Facultat, el professor Frederic Udina, persona conservadora, anava a la comissaria de la Via Laietana per intentar que no li torturessin els estudiants detinguts en un dels molts estats d'excepció, i quan el governador civil de Girona va expulsar una professora de Geografia, va fer canviar el pla docent a l'Enric dient-li: «Posa-la al segon semestre i ja no se'n recordarà».

Des dels inicis, la lluita per una universitat democràtica, autònoma $\mathrm{i}$ catalana va formar part del nostre $\mathrm{ADN}$ i, al cap de vint-i-cinc anys, la UAB va premiar amb la medalla de la institució bastants docents de Geografia, que devíem ser, proporcionalment, el departament més representat. Les lluites del professorat no numerari (PNN) varen representar una combinació entre la millora laboral i l'oposició política al règim dictatorial, i en aquest sentit el curs 1974-1975 es va iniciar amb una vaga indefinida que va comportar l'anomenat «aprovat col-lectiu». Al Departament hi havia dues tendències ben clares: l'una volia delimitar la vaga, i l'altra, perllongar-la. Finalment es va imposar aquesta darrera a la major part de centres de la UAB. No hi havia classes reglades, però es realitzaven moltes activitats i classes fora de les aules, també es va elaborar un manifest polític radical des de l'extrema esquerra. El Govern de l'Estat va suspendre els estatuts de la UAB i llavors es va convocar un claustre extraordinari el dia 15 de març de 1975, a partir del qual es va elaborar el Manifest de Bellaterra de 1975 (Riquer i Molinero, 2018), amb la participació d'Enric Lluch, que presentava els elements necessaris perquè la universitat $\mathrm{i}$ la societat esdevinguessin democràtiques, autònomes i catalanes. La UAB va ser, encara en vida del dictador, el primer centre d'educació superior que es manifestava públicament en defensa de les llibertats polítiques, fet que va incrementar l'hostilitat de les autoritats ministerials en contra de la nostra institució.

El professorat del Departament estava compromès amb el moviment dels PNN i va col-laborar en la fundació de Comissions Obreres (CCOO) a la UAB el 1976, juntament amb Giulia Adinolfi de Filologia. Des de les primeres eleccions democràtiques, alguns professors varen tenir responsabilitats en ajuntaments, al Parlament de Catalunya i a les Corts Generals espanyoles. El compromís amb la societat civil i l'acció política parlamentària o extraparlamentària va ser una constant en la història del Departament d'aquells primers anys.

\section{Els plans d'estudis de la geografia a la UAB}

La participació de la geografia en diversos estudis de la UAB al llarg dels primers vint anys va mostrar tres períodes ben definits. Des de 1968 s'hi va desenvolupar el Pla Udina, que va rebre el nom del degà, a la Facultat de Lletres. Aquest pla donava molta flexibilitat en l'elecció de les assignatures durant els dos primers cursos. L'any 1973, el ministre d'Educació, Julio Rodríguez Martínez, imposà el Pla Suárez a tot l'Estat, amb la novetat que es regia pel calen- 
dari julià (de gener a desembre), cosa que no va reeixir, i el 1977 el Ministeri d'Educació i Ciència implantà un nou pla d'estudis més flexible i d'aplicació més autònoma per part de les diferents universitats.

\subsection{Els centres on s'impartia geografia}

Els estudis de geografia es van iniciar al centre escolar de Can Magí, a Sant Cugat del Vallès, el curs 1969-1970, com tota la docència de la Facultat de Lletres. Paral-lelament, se'n van fer classes a la Casa de Cultura de Girona (Col-legi Universitari, CUG) l'any 1969. Des de l'any acadèmic 1970-1971, la docència es va traslladar a la Casa de Cultura i després al claustre del monestir de Sant Cugat del Vallès (Facultat de Lletres), i també es va fer docència a la Facultat de Ciències de la Informació, que va ser de les primeres que es va traslladar al campus de Bellaterra. La Facultat de Lletres hi va anar el curs 1973-1974. Durant els anys acadèmics 1972-1973 i 1973-1974 també s'impartia ensenyament a la Facultat de Lletres de Lleida, que s'havia adscrit a la UAB. Tanmateix, el 1974 hi va haver un acord de permuta de centres entre la UB i la UAB, que adscrivia l'esmentada facultat a la UB i, en canvi, l'Escola de Mestres de Lleida, que ja tenia el seu professorat, es va adscriure a la UAB el curs 1974-1975. La seu del professorat (seminaris, sales de reunió i despatxos) estava situada inicialment a les cases de cultura de Sant Cugat i de Girona.

El curs 1973-1974 es van iniciar les classes al campus de Bellaterra i els sis despatxos de Geografia estaven situats enfront del Deganat i de la Secretaria de la Facultat de Lletres (Espiga B9 parell, primer pis). Més endavant es varen anar ocupant algunes aules de la mateixa Espiga, a la planta baixa, per a usos específics (IUET, cartoteca, laboratori de geografia física, etc.) i despatxos. A més d'impartir docència a la Facultat de Ciències de la Informació també es va intervenir en la Facultat de Ciències Econòmiques i en les escoles universitàries de traducció i d'interpretació i de professorat d'EGB. Durant el curs 1988-1989 es va formar part de la gestora per promoure els estudis de Ciències Ambientals a la Facultat de Ciències. En el CUG, Lletres es va traslladar a l'antic seminari el $1976 \mathrm{i}$ hi va romandre durant molts anys, fins a la creació de la nova facultat i cartoteca al convent de Sant Domènec (vella caserna militar), a començaments de l'any 1993. La biblioteca hi va ser instal-lada uns quants mesos més tard. El rectorat de la Universitat de Girona va ubicar-se a l'edifici de les Àligues durant el curs 1992-1993.

Es pot considerar que la geografia, amb titulació o sense, va tenir i té la vocació d'aportar coneixements específics amb una visió global del món i de la societat amb aproximacions innovadores. També va saber acollir i desenvolupar matèries com ara la demografia o els sistemes d'informació geogràfica, així com aplicar l'enfocament de l'ordenació del territori i el planejament en altres disciplines. En crear-se la Facultat de Ciències Polítiques i Sociologia (1986), Enric Lluch va explorar la possibilitat que la geografia, com a ciència social, s'hi ubiqués, ja que s'hi impartia la demografia (assignatura troncal) i es parlava d'una geografia política (optativa). La geografia havia participat sempre 
en les diverses iniciatives de creació de nous estudis, on tenia lloc juntament amb matèries afins. En aquest sentit, va ser ben rebuda en altres disciplines i, sovint, si va deixar d'impartir-s'hi va ser més per corporativisme de les àrees de coneixement i els grups de poder dels centres que no pas perquè deixés d'interessar la participació de la geografia i àmbits semblants en els currículums. Pot afirmar-se que cada canvi de pla d'estudis va posar en perill la continuïtat de la geografia en les disciplines corresponents.

\subsection{Pla Udina (1969-1970)}

La llicenciatura universitària a la Facultat de Lletres de Sant Cugat s'estructurava en dos cicles i cinc cursos, amb cinc assignatures anuals cadascun. En el primer cicle, que constava de tres cursos, es podien escollir quatre assignatures entre grups tancats d'aquestes segons l'especialitat que es volgués seguir a segon cicle, i una cinquena era de lliure elecció. El segon cicle, format per dos cursos, contemplava les especialitats, que es corresponien amb departaments (Filosofia, Filologia Clàssica, Filologia Hispànica, Llengües Modernes, Art, Història i Psicologia). El Departament de Ciències Socials, on hi havia la Geografia i la Sociologia, era transversal. Aquest mateix model s'oferia a la Casa de Cultura de Girona (1969) i a Lleida (1972).

El curs 1969-1970 es va oferir la Introducció a la Geografia en un grup de cinc assignatures (Història, Geografia, Filosofia, Català i Llatí), de les quals l'estudiant n'havia de triar tres. A més, podia ser escollida com a lliure. L'actitud dels dos professors (Enric Lluch i M. Dolors Garcia Ramon) va ser atraure el nombre més elevat possible d'estudiants de la Facultat amb docència innovadora i crítica, així com organitzar moltes pràctiques i sortides de camp. A Sant Cugat hi havia dos grups amb 130 alumnes que compartien els esmentats professors, i a Girona també dos grups amb 115 alumnes repartits entre Enric Lluch i Montserrat Moli. El contingut abraçava Pensament Geogràfic, Geografia Humana i Geografia Física, amb dues excursions sobre rudiments de geografia física, humana i de la regió. També s'hi impartia sociologia.

A títol il.lustratiu, cal fixar-se en l'oferta d'assignatures a primer, el curs 1969-1970, a la Facultat de Lletres, tant a Sant Cugat com a Girona: Llengua Llatina-I, Llengua Grega-I, Llengua Castellana-I, Llengua Catalana-I, Fonaments Filosòfics-I (Fonaments de Filosofia, a Girona), Sociologia-I, Història de l'Art, Introducció a la Geografia, Història d'Espanya i Introducció a la Teologia. A segon i a tercer l'alumnat havia d'escollir la meitat de les assignatures entre les recomanades pels departaments per poder passar al segon cicle de les especialitats respectives. Com que la geografia no tenia departament propi, no podia organitzar un segon cicle i els universitaris que volien ser geògrafs havien de marxar a la UB, per aquest motiu eren anomenats «l'estudiantat de la diàspora».

El curs 1970-1971 s'oferia la Introducció a la Geografia (dos grups a Sant Cugat i un a Girona) i la Geografia d'Espanya (a Sant Cugat i a Girona). L'any 1971-1972 hi havia quatre grups d'Introducció a la Geografia a Sant Cugat (Lletres) i dos a la Facultat de Ciències de la Informació, i un de Geografia 
d'Espanya, de Geografia General (Urbana) i de Geografia de Gran Bretanya i els Estats Units d'Amèrica. A Girona també hi havia un grup d'Introducció a la Geografia i un de Geografia General (Urbana). En tots dos centres s'impartia Sociologia I i Sociologia II.

Durant el curs 1972-1973 s'incrementà l'oferta docent de forma significativa: Introducció a la Geografia (deu grups a Lletres Sant Cugat, tres a Ciències de la Informació, dos a Girona i un a Lleida); Geografia General -Urbana- (dos grups a Sant Cugat i dos a Girona); Introducció a les Ciències Socials-Geografia Humana (a Sant Cugat); Geografia de França (a Sant Cugat); Geografia dels Països de Parla Anglesa (a Sant Cugat); Geografia d'Espanya (a Sant Cugat, Girona i Lleida); Sociologia-I (a Sant Cugat i Girona), i Sociologia-II (a Sant Cugat).

El curs 1973-1974 s'implantà el Pla Suárez a primer any, mentre es continuà el Pla Udina de segon a quart fins al 1976-1977, on les assignatures de Geografia eren únicament al primer cicle.

\subsection{Pla Suàrez (1973-1974)}

Aquest nou pla va permetre crear un departament propi de geografia i la llicenciatura completa amb assignatures comunes amb Història i Art, i la facultat va proposar, el 15 de febrer de 1972, la creació de la Divisió de Geografia. El trasllat de la Facultat de Lletres des de Sant Cugat fins a Bellaterra va retardar l'inici de curs fins al 20 d'octubre de 1973 per problemes d'obres. Davant de les expectatives del nou pla, la Divisió de Geografia va proposar que s'hi anessin incorporant assignatures com ara Geografia Urbana, Geografia Rural, Ecologia Humana (el Medi i l'Home), Geografia de l'Àrea Catalana, Geografia d'una Regió Mundial, Cartografia i Fotointerpretació, i també matèries afins, com ara Matemàtiques i Estadística Aplicada a les Ciències Socials, Economia Política I, Economia Política II o Demografia (orientada als historiadors).

Tanmateix, l'aplicació del Pla Suarez ${ }^{10}$ va comportar un primer curs més «tancat» del que s'havia previst. Anava dirigit a les llicenciatures d'Art, de Geografia i d'Història, amb les assignatures següents: Prehistòria, Llengua Llatina (substituïda per Estadística Aplicada a les Ciències Socials), Introducció a l'Art i Geografia General-I. A més, l'alumnat d'Història i el de Geografia s'havia de matricular a Introducció a les Ciències Històriques; i el d'Art, a Història de l'Art-I.

Durant el segon any es cursava Història Antiga, Història Medieval, Historia de la Filosofia i Geografia Descriptiva. Els universitaris de Geografia i d'Història podien estudiar Geografia General-II o Història General-II indistintament, mentre que els d'Art cursaven Història de l'Art-II.

Al llarg del tercer any es feia Història Moderna, Història Contemporània, Història de la Literatura i Geografia d'Espanya. L'alumnat d'Història i de Geo-

10. El BOE de 19 de gener de 1974 publicava la «Resolución de la Dirección General de Universidades del Plan de estudios de Primer Ciclo de la Facultad de Filosofía y Letras de la UAB». 
grafia podia matricular-se indistintament a Geografia General-III o a Història General-III, mentre que el d'Art feia Història de l'Art-III.

El segon cicle de Geografia s'organitzava en dos cursos. Al primer hi havia Climatologia i Biogeografia, Geografia de la Població, Geografia Econòmica i Geografia Urbana. Al segon, Geografia Agrària, Geografia Descriptiva, Geografia Regional d'Espanya i Geomorfologia. Tanmateix, en el curs 1976-1977 aquest segon cicle es va transformar en àrees temàtiques que es mantindrien en el nou pla d'estudis (1977-1978) i fins a la dècada de 1990.

El Pla Docent 1973-1974 ens dona una idea de l'activitat de la divisió de Geografia a Bellaterra (B), a la Facultat de Filosofia i Lletres (B-FF) o en altres centres, a Girona $(\mathrm{G})$ i a Lleida (Ll): Geografia General I (deu grups a B-FF, dos a B-CC. Informació, dos a G i dos a Ll); Geografia d'Espanya (dos a B-FF i un a G); Geografia General II (un B-FF i un G); Iniciació a les Ciències Socials (un B-FF); Geografia de França (un a B-FF) i Geografia dels Països de Parla Anglesa (un a B-FF) a Llengües Modernes; Història Social i Econòmica de la Guerra (un a B-FF, Història); Sociologia I (un a B-FF) i Sociologia II (un a B-Econòmiques); Sociologia de les Migracions (un a B-Econòmiques); Sociologia de les Classes Socials (un a B-Econòmiques), i Didàctica de la Geografia (un a B-ICE).

El contingut de la Geografia General-I incloïa Pensament Geogràfic, Introducció a l'Estudi del Medi Físic i Geografia Humana (Població, Urbana i Rural). La Geografia General-II contenia tres parts: Geografia Humana com un Sistema Espacial Urbà, Geografia Física (Climatologia i Geomorfologia) i Activitats Agràries i Món Rural. La Geografia Descriptiva se centrava en quatre temes: Xina, Itàlia, Crisi Energètica i Mercat Comú. La Geografia d'Espanya incloïa Geografia de Catalunya, de la qual es tractaven els aspectes físics i socioeconòmics.

Durant el curs 1974-1975 es van impartir, a la recentment creada Escola Universitària de Traductors i Intèrprets, les assignatures de Geografia de França, Geografia d'Anglaterra i Geografia Econòmica d'Espanya. A l'Escola Universitària de Professorat d'EGB s'hi ensenyava Didàctica de la Geografia, Geografia General, Pràctiques de Geografia I i Pràctiques de Geografia II. A Girona s'amplià la docència amb Geografia Humana i Estadística Aplicada a les Ciències Socials. A la Facultat de Filosofia i Lletres s'establia un horari de matí i un de tarda (de 16 a 19 hores) únicament per a tres especialitats, entre les quals hi havia Història amb la participació de Geografia.

El curs 1975-1976 ja s'oferien els tres primers anys del Pla Suárez amb les assignatures impartides des de Geografia. A primer hi havia Geografia General-I, amb sis grups, i Estadística Aplicada a les Ciències Socials, amb tres grups. A segon, Geografia-II (Geografia Humana), amb quatre grups; Geografia Descriptiva, amb quatre grups, i Fonaments d'Economia, amb tres grups. A tercer, Geografia d'Espanya, amb tres grups, i Geografia-III, amb dos grups. Es continuava amb el Pla Udina: Geografia d'Espanya, Geografia General (Urbana), Introducció a les Ciències Socials, Geografia de França, Geografia i Institucions dels Països de Parla Anglesa, Introducció a l'Economia, Sociologia i Geografia Física. 
Es va mantenir la mateixa docència a Bellaterra: Llengües Modernes, les assignatures optatives de la Facultat de Filosofia i Lletres i de la Facultat de Ciències Econòmiques, a la Facultat de Ciències de la Informació, a l'Escola Universitària de Traducció i Interpretació i a l'Escola Universitària de Professorat d'EGB. En canvi, hi va haver un augment substancial al CUG, que va passar de cinc a vuit grups amb noves assignatures, com ara Fonaments d'Economia, Geografia Descriptiva i Geografia III.

El curs 1976-1977 va continuar en els mateixos termes, però a partir de l'aplicació del nou pla (1977-1978) hi va haver, per un cantó, un reforçament de la titulació de Geografia, mentre que, per l'altre, es va anar perdent gradualment la presència a les facultats de Ciències Econòmiques, de Ciències de la Informació i de l'Escola Universitària de Traducció i Interpretació, així com en les titulacions de Llengua Anglesa i Llengua Francesa.

\subsection{Nou pla d'estudis (NPE) 1977-1978}

Tanmateix, tant en el Pla Suárez com en el nou pla (O. M. de 26 de setembre de 1977; BOE de 16 de novembre de 1977), era facil passar de la titulació d'Història a la de Geografia matriculant-se en molt poques assignatures de més, fins i tot en cap. Llavors, el professorat de Geografia a primer i a segon feien les classes molt atractives per captar estudiants d'Història, ja que la geografia mai no havia tingut un paper rellevant en la docència de batxillerat i no atreia de bell antuvi. El fet que la llicenciatura d'Història s'oferís en horari de tarda va permetre que s'hi incloguessin assignatures de Geografia, que ja arribaven a ser set durant el curs 1982-1983. Això va facilitar la inclusió de la llicenciatura de Geografia a la tarda, amb quinze assignatures el curs 1983-1984. En referència a la captació d'universitaris cap als estudis de geografia, també cal remarcar la importància del curs pont per als mestres d'EGB des de l'any acadèmic 1978-1979.

La Facultat de Lletres va arribar a tenir més de 4.000 alumnes durant el curs 1977-1978. Estava constituïda per seccions designades habitualment com a departaments que corresponien a les unitats de docència i d'investigació, la qual cosa donava lloc a les titulacions establertes en el Pla Suárez.

El pla d'estudis de la Facultat, que incloïa l'especialitat de Geografia, fou presentat al Ministeri d'Educació i Ciència el dia 3 de juny de 1977 i aplicat al llarg del curs 1977-1978, amb la normativa d'adaptació dels que havien començat els estudis en el Pla Suárez. Les tres característiques més importants del nou programa eren:

a) Una llista restringida d'assignatures durant el primer curs per a les onze seccions que podien fer les recomanacions oportunes. Al principi n'hi havia 22, entre les quals s'hi podia trobar Geografia Humana, Geografia Física-I, Matemàtiques de les Ciències Humanes-I i Economia-I, sota la responsabilitat de la Secció de Geografia.

b) Una oferta d'assignatures a segon i a tercer curs, on, a part de les que oferia la Secció de Geografia, també es recomanaven matèries d'altres seccions, 
amb un mínim de tres que es podien escollir entre un total de vuit de la Secció d'Història. De les quinze assignatures anuals dels tres cursos de primer cicle únicament n'hi havia sis d'obligatòries, les altres eren optatives.

c) El segon cicle, amb deu assignatures anuals repartides en dos cursos, comportava escollir un mínim de set matèries de l'especialitat i fins a tres de qualsevol altra especialitat o estudi en el si de la UAB. Les assignatures, que podien modificar-se any rere any, estaven adscrites a unes àrees que eren les inamovibles en el nou pla d'estudis.

Per obtenir el títol de llicenciat en Geografia (Facultat de Filosofia i Lletres), des del curs 1977-1978 s'havien d'estudiar a primer cicle les assignatures anuals obligatòries de Geografia Humana-I i Economia-I, a primer curs; de Matemàtiques de les Ciències Humanes-I i Geografia Física-I, a segon curs, i de Geografia d'Espanya i Cartografia i Fotointerpretació, a tercer curs. També s'havia de triar un mínim de tres assignatures de la Secció d'Història entre les següents: Introducció a les Ciències Històriques, Història Medieval, Història Moderna, Història Contemporània, Història d'Espanya, Història de Catalunya, Història Econòmica i Antropologia Cultural. Així mateix, s'havia d'escollir un mínim de tres assignatures optatives de les programades per la Secció de Geografia: Geografia Física II (Geomorfologia), Geografia Física III (Biogeografia), Geografia Rural, Geografia Urbana, Geografia de la Població, Anàlisi Territorial, Geografia Regional i Geografia dels Països Catalans. Entre les tres optatives, s'aconsellaven la Demografia i la Sociologia, impartides a Geografia i que formaven part d'un bloc de matèries que oferia la Facultat sense adscripció explícita a cap secció.

El segon cicle del NPE establia un disseny poc habitual en la tradició acadèmica espanyola, atès que s'aprovaven àrees de coneixement a les quals es podien assignar matèries diferents cada any. Aquesta estructura, igual a tota la Facultat, segurament va ser aprovada per presentar-se en bloc totes les titulacions. Les àrees de la Secció de Geografia eren les següents:

1) Epistemologia i Metodologia de la Geografia.

2) Estudis del Medi Físic i dels Recursos Naturals.

3) Estudis de la Població i de les Activitats Socials i Econòmiques.

4) Estudis d'Anàlisi i Planificació del Territori.

5) Estudis Regionals.

6) Tècniques Professionals.

Cada estudiant havia de triar matèries de com a mínim tres camps diferents. Era obligatori escollir-ne una de l'àrea primera i una altra de l'àrea sisena. A tall d'exemple, les assignatures ofertes entre els cursos 1977-1978 i 1978-1979 (posant entre parèntesis el número de l'àrea) foren: Pensament Geogràfic (1), Anàlisi Matemàtica en Geografia (1), Metodologia de la Geografia Física (2), Sistemes Econòmics (3), Geografia de la Població-II (3), Població d'Espanya (3), Geografia Rural-II (3), Anàlisi i Planificació Territorial (4), Anàlisi Territorial-II (4), Tècniques Professionals (6) i Didàctica de la Geografia (6). 
Es varen organitzar uns «estudis troncals» que agrupaven a l'entorn de tres assignatures d'un curs. Durant l'any acadèmic 1977-1978 l'objectiu era delimitar les àrees educatives de Catalunya; el 1978-1979, les àrees sanitàries, i el 1979-1980, les àrees veterinàries. Al llarg dels cursos 1986-1987 i 1987-1988, aprofitant una subvenció del Projecte MAB-6 que permetia que es realitzés un treball de camp de cinc dies a una trentena d'estudiants allotjats a l'Escola Professional Agrària de Bellestar, es va realitzar la diagnosi i la prognosi del desenvolupament local de les Valls de Tuixén-La Vansa i de Castellbó, respectivament. Aquest model es va repetir al llarg de divuit edicions amb temàtica diversa, per exemple: l'impacte de noves vies de comunicació o el planejament rural. Llavors, les assignatures implicades desenvolupaven un programa propi durant els primers mesos i després cada grup de dos o tres universitaris elaborava una memòria amb l'assessorament col-lectiu i individualitzat del professorat implicat. La utilitat del mètode troncal era combinar l'estudi de cada temàtica amb una visió més global d'ordenació territorial i de planejament, i pretenia ser un inici de la recerca amb l'elaboració d'un treball en grup i realitzant treball de camp.

Aquest NPE, de 1977-1978 a 1990-1991 ${ }^{11}$, i tres anys més d'adaptació, va permetre aplicar amb maduresa el que es va iniciar en el període 1969-1973 amb la introducció de la Geografia en els estudis de la Facultat de Lletres i que va obrir el camí de l'especialització amb el Pla Suárez (1973-1977). El NPE, amb un equip de professorat del Departament de Geografia consolidat (quinze al «corredor de Geografia», cinc a l'Escola de Mestres de Sant Cugat, tres al Col-legi Universitari de Girona i tres a l'Escola de Mestres de Lleida), va poder desenvolupar l'enfocament de la geografia que el professor Enric Lluch havia anat construint amb els seus contactes internacionals, els moviments pedagògics i els debats acadèmics.

\subsection{El doctorat de Geografia i els membres del Departament que eren doctors}

La Facultat de Lletres tenia competència en estudis de doctorat des de la seva fundació. Es requeria haver presentat una memòria de llicenciatura anomenada tesina i assistir a un mínim de tres cursos monogràfics, a més de treballar en la preparació de la tesi doctoral corresponent. Els cursos es podien seguir en qualsevol facultat de la UAB i fins i tot en altres universitats. El nom de la facultat on es presentava havia de sortir en el títol, amb l'especialitat entre parèntesis. Des del Decret de 6 de maig de 1977 (BOE de 7 de maig de 1977) i els acords de la Junta de Facultat de 9 de febrer de 1977, es podia presentar el text en català o en castellà indistintament $\mathrm{i}$ en altres llengües amb aprovació

11. L'any 1991 s'aprova un nou pla d'estudis (R. D. 1380/91; BOE de 28 de setembre de 1991) de 4 anys i 300 crèdits a la Facultat de Filosofia i Lletres, que s’inicia el 1991-1992 i que coexisteix amb l'anterior durant tres cursos. La diferència principal serà l'organització semestral de les assignatures, que seran troncals, obligatòries, optatives i de lliure elecció. El document de cada titulació en l'àmbit de l'Estat espanyol és l'anomenat «lechuga», pel color verd de les tapes. 
prèvia de la Junta. No hi havia un temps limitat per presentar la tesi, però el curs 1988-1989 es va establir l'obligació de fer els cursos en dos anys.

Durant els primers temps no va haver-hi cap membre del grup que fos doctor, a part dels tres numeraris que varen venir d'altres universitats (Eusebio Garcia Manrique, Carmen Ocaña i Eugeni Burriel) i del professor adjunt de Sociologia (Juli Busquets). M. Dolors Garcia Ramon fou la primera doctora del grup (UB, juliol de 1975, director Joan Vilà Valentí) i el gener de 1982 presentaven a la UAB les tesis doctorals Helena Estalella (director Ramon Garrabou) i Antoni F. Tulla (director Jordi Nadal i Oller). Àngels Pascual la va llegir a la Facultat de Ciències Econòmiques l'any 1983 (director Jordi Nadal i Oller) i des de llavors es varen anar realitzant tesis doctorals del professorat del Departament fins que el curs 1990-1991 hi va arribar a haver disset doctors. També s'hi va incorporar Manuel Miró, de Geografia Física, que ja era doctor.

Es varen impartir cursos de doctorat de Geografia a la Facultat des de 19771978, amb Eugeni Burriel (Anàlisi de la Població Espanyola en el Segle XX) i M. Dolors Garcia Ramon (Tècniques en Geografia Rural), que els anys següents varen ser Problemes de la Població Espanyola Contemporània i Pensament Geogràfic Anglosaxó. Durant l'any acadèmic 1982-1983, Antoni F. Tulla va ensenyar Geografia de Muntanya. L'Estructura de les Explotacions Ramaderes al Pirineu, i el 1983-1984, Helena Estalella, Problemàtica de l'Explotació Agrària en l'Actual Crisi Econòmica. El 1984-1985, M. Dolors Garcia Ramon va impartir Els Nous Enfocaments en la Geografia Anglosaxona i la Repercussió en la Geografia Catalana i en l'Espanyola. A mesura que el professorat del Departament anava aconseguint el doctorat va anar passant a fent cursos de forma rotatòria.

L'any 1986-1987 es va decidir formalitzar el programa de doctorat en Geografia ${ }^{12}$, que era una decisió compromesa del Departament per fer un canvi qualitatiu en l'ensenyament de la geografia. La UAB va anomenar M. Dolors Garcia Ramon coordinadora del programa, que funcionava pel sistema de crèdits i que havia d'incloure professorat extern de prestigi reconegut. Entre aquestes aportacions va haver-hi les de Lluís Solé Sugrañes, de l'Institut Jaume Almera (CSIC), amb un curs anomenat Teledetecció des de 1986, i de Françoise Breton, de la Diputació de Barcelona, que impartia Pesca i Gestió del Litoral des de 1988, tots dos sense remuneració. Cal fer esment que en aquests vint anys inicials no es comptabilitzaven com a dedicació docent ni els cursos de doctorat ni la direcció de tesis doctorals.

\section{El capital humà del Departament de Geografia}

La cerca del professorat per part d'Enric Lluch va obeir a uns objectius clars:

1) Prioritzar una docència innovadora en els continguts i la pedagogia adient per impartir-los.

12. RD 185/1985, de 23 de gener, que regula el tercer cicle d'estudis universitaris i l'obtenció i l'expedició del títol de doctor (BOE, 69, 7.286). 
2) Incorporar-hi experiències i coneixements de la geografia d'altres països.

3) Reforçar una base interdisciplinària en l'ensenyament de la geografia.

4) Permetre realitzar un treball en equip per fer front al repte de nous enfocaments en les assignatures que calia impartir.

5) Assegurar una formació continuada que fes possible aquesta nova geografia, tant des del punt de vista de la docència com de la recerca.

La captació específica del professorat va dependre més de les oportunitats que van anar sorgint per contractar-lo que no pas perquè hi hagués un pla organitzat. Es va anar consolidant un nombre significatiu d'ensenyants des que la geografia s'impartia únicament a la Facultat de Lletres (Sant Cugat i CUG) com una disciplina auxiliar l'any 1969, fins a la creació de la titulació de Geografia el curs 1973-1974, passant per les assignatures de geografia en altres estudis. Aquesta consolidació dels estudis de geografia pot considerar-se que s'institucionalitzaria amb la constitució del Departament de Geografia de la UAB el 7 de desembre de 1985 (annex I).

A l'annex II $(a, b, c)^{13}$ s'hi presenta una relació de tot el professorat - a les seus de Sant Cugat-Bellaterra, Girona i Lleida — involucrat en l'ensenyament de les assignatures dependents, primer del Departament de Ciències Socials, després de la Divisió de Geografia «corredor», i, des de 1985, del Departament de Geografia LRU. Si ens centrem en la docència estricta de la geografia, Enric Lluch i M. Dolors Garcia Ramon varen ser els primers, juntament amb Montserrat Moli al CUG, a qui s'hi van afegir, l'octubre de 1970, Helena Estalella i Jordi Borja, i, a l'abril de 1971, Laura Zumin. Juli Busquets i Antoni F. Tulla, professors de Sociologia, s'aixoplugaven amb els geògrafs, fet que va provocar que aquest darrer "passés» a aquesta disciplina després d'anar dos anys al Departament de Geografia de la Universitat de Bristol. L'increment del professorat va tenir lloc juntament amb la demanda de noves assignatures en diversos centres de la UAB. Sovint es buscaven economistes o enginyers per a la docència de l'economia, les matemàtiques, l'estadística o la informàtica, $\mathrm{i}$ n'hi va haver alguns (Eugeni Giral o Emili Gasch) que també varen impartir Introducció de la Geografia a Ciències de la Informació.

Al començament, les classes a Girona i a Lleida les impartien docents de Sant Cugat o de Bellaterra, però amb els anys s'hi va anar incorporant professorat del lloc, encara que fins a meitat de la dècada de 1980 és viatjava a Girona des de la UAB. Podria considerar-se que la constitució del Departament de Geografia, en el marc del desenvolupament de la LRU, a Saifores ${ }^{14}$ (municipi de Banyeres del Penedès) representà la consolidació institucional de la geografia a la UAB, amb 29 professors i professores, 20 dels quals pertanyien a cossos docents (annex I).

Ens ha semblat oportú presentar a l'annex III el cens dels cossos docents de Geografia (abril de 1992) classificat per universitats de l'Estat espanyol, a fi

13. El professorat ha estat agrupat en tres blocs: Sant Cugat-Bellaterra, Girona i Lleida.

14. A la casa que ens va cedir Marta Mata, per amistat amb Enric Lluch, que volia que el nou departament es constituís en un lloc territorialment neutre, fora dels tres centres de docència. 
de poder demostrar que després de 22 anys «la geografia institucionalitzada» de la UAB es trobava entre la de les cinc universitats més importants, fet que va sorprendre més d'un catedràtic d'altres universitats quan se'n van assabentar. Si féssim set grups d'acord amb el nombre de membres dels cossos docents, tindríem el següient: primer ( 2 universitats de més de 30 professors i professores): Complutense i Barcelona; segon (3, de 25 a 29): Autònoma de Madrid, Autònoma de Barcelona i València; tercer (4, de 20 a 24): Granada, Sevilla, Saragossa i Oviedo; quart (2, de 15 a 19): Alacant i La Laguna; cinquè (5, de 10 a 14): Múrcia, Santiago, UNED, Cantàbria i Valladolid; sisè (10, de 5 a 9): Castella-la Manxa, Màlaga, Balears, Extremadura, Las Palmas de Gran Canaria, Lleó, Salamanca, Alcalá de Henares, País Basc i Còrdova, i setè (3, de menys de 5): Cadis, Pública de Navarra i Vigo.

Aquesta estructura mostra que la $\mathrm{UAB}^{15}$ està entre les cinc universitats grans, de més de 25 professors i professores, mentre que n'hi ha 13 de petites (menys de 10) i 11 de mitjanes (entre 10 i 24). Cal tenir en compte, però, que des de 1992 hi haurà un esclat de noves universitats, especialment a Catalunya, que modificaran aquesta estructura. Amb tot, el setembre de 1995, amb 39 universitats que tenien cossos de professorat en geografia, a la UAB encara n'hi havia 25; a Girona, 8; a la Rovira i Virgili, 6; a Lleida, 5, i a la Pompeu Fabra, 1. Dels docents de la UAB, n'hi havia 10 (un 40\%) que havien realitzat estudis o estades llargues en universitats estrangeres. A títol il.lustratiu, la primera participació oficial de professorat del Departament (Pau Alegre, M. Dolors Garcia Ramon, Lluís Riudor i Antoni F. Tulla) en un congrés estatal va ser a la Universitat de Granada l'any 1978 (V Coloquio de Geografía de la AGE: Los paisajes rurales en España), on es van presentar comunicacions d'enfocament geogràfic marxista i radical.

La qualitat del professorat en docència, recerca, capacitat organitzativa i visió estratègica dels estudis universitaris va fer possible aquesta realitat. Tanmateix, una persona important en l'Àrea de Personal Docent va comentar l'any 1986 que al «Rectorat [de l'Autònoma] ningú no donava un duro pel futur de la geografia a la UAB». Des del primer any es va ser rigorós a fer la feina, formant-se, estant al dia del que succeïa al món i buscant complicitats per poder demostrar que la geografia era útil en els ensenyaments universitaris d'Humanitats i de Ciències Socials. Amb tot, els deu primers anys (1969-1980) es va deixar de costat l'elaboració de les tesis doctorals, tret de comptades excepcions, i va ser a la segona dècada (1980-1990) quan hi va haver una voluntat clara de promoure-les. En perdre l'oportunitat del «contracte laboral» amb la LRU (1983) es va confeccionar un pla col-lectiu per doctorar-se i concursar a les places dels nous cossos docents, fins i tot amb una bossa comuna de salaris per

15. Àrea de coneixement de Geografia Humana: P. Alegre, R. Ascon, A. Cabré, G. Cànoves, M.D. Garcia, J. Domingo, H. Estalella, R. Fraguell, C. Gonzalo, F. Muñoz Pradas, J. Nogué, A. Pascual, Gerda K. Priestley, P. Riera, L. Riudor, D. Salvany, D. Saurí, M. Solsona, A. Torrents, A.F. Tulla i M. Villanueva. En Didàctica de les Ciències Socials: P. Benejam i J. Díaz. En Geografia Física: M.P. Mazarico, M. Miró, J. Sabí i A. Xercavins. Enric Lluch TU homologat (Consejo de Universidades, 1987). 
facilitar l'esmentat pla. L'accés al funcionariat també va seguir un full de ruta, gràcies al qual els membres del professorat s'ajudaven, a fi de poder disposar de temps per preparar-se les proves dels concursos.

La part més jove dels recursos humans corresponia als becaris i a les becàries dels programes de formació d'investigadors del MEC, primer, i de la Generalitat de Catalunya/UAB o dels instituts de recerca, més endavant. En bona part això ho facilitava la recerca iniciada durant la dècada de 1980, que va culminar en projectes competitius obtinguts en convocatòries públiques. Des de 1981 fins a 1990 varen concedir-se quinze beques predoctorals (annex IV), circumstància que també mostra el dinamisme del Departament. Dels quinze becaris, n'hi va haver set que varen realitzar la tesi doctoral. Varen continuar en el món acadèmic vuit dels becaris d'aquest període. Els que no ho varen fer va ser perquè volien trobar feina fora del món universitari (Diputació de Barcelona, Generalitat de Catalunya, ajuntaments, Entitat Autònoma del Port de Barcelona o consultories professionals) i pel llarg "camí acadèmic» que calia recórrer, més que no pas per manca d'interès.

\section{Governança del Departament de Geografia}

El treball en equip, juntament amb uns objectius ben definits, han estat la base de funcionament del grup de geògrafs i geògrafes a la UAB. No únicament en la gestió, sinó també en la preparació docent i en la realització de la recerca. Les reunions, grans i petites, han estat l'escenari per avançar. Des de la formació fins a les preses de decisió col-lectives.

Des dels primers anys, tots els membres del professorat treballaven en grup en la preparació i la impartició de la docència, així com en l'avaluació col.lectiva de l'alumnat. La direcció del Departament sempre ha estat col-lectiva (annex V), des de l'anomenada "troika», grup de tres docents en la direcció, encara que n'hi hagués un que n'assumís la representació, fins a la direcció del departament LRU (director i secretari acadèmic), ajudada per una comissió executiva amb responsabilitats delimitades de cadascun dels seus membres. En els primers anys cada ensenyant tenia una responsabilitat concreta que "despatxava» amb un representant de la troika, mentre que, en haver-hi una comissió executiva, era en aquesta comissió on es discutia la problemàtica de cada responsable de les tasques departamentals.

Finalment, cal esmentar que des de l'any acadèmic 1974-1975 tot el professorat va passar a ser «encarregat de curs» contractat, amb l'excepció del catedràtic numerari de Geografia (Eusebio García Manrique), de l'adjunt numerari de Sociologia (Juli Busquets) i de tres adjunties contractades que corresponien a M. Dolors Garcia Ramon, Maria Villanueva i Antoni F. Tulla. El curs 19751976 s'hi incorporà com a adjunta numerària Carmen Ocaña. Llavors es va plantejar fer un "pool de sous" entre la major part del professorat no numerari (PNN) al "corredor de Bellaterra», acció que es va perllongar durant catorze anys, fins que les retencions de renda i diverses discrepàncies sorgides entre el col.lectiu ho va fer inviable. A tall d'exemple, l'any 1985 eren catorze perso- 
nes amb un volum de sou net mensual de quasi 1.400 .000 pessetes $(100.000$ pessetes per cap) i un transvasament de 115.705 pessetes (un 8,5\%) entre els membres. L'incentiu per fer la tesi doctoral era important, ja que es passava d'encarregat de curs a professor adjunt contractat o interí i més endavant fins $\mathrm{i}$ tot a catedràtic interí, ja que n'hi va haver una plaça vacant durant molts anys. Aquest fet implicava que els sous milloraven per l'augment oficial, però també perquè algun professor o professora passava a una categoria més ben remunerada. El Pla Nadal (pel nom del vicerector Josep Nadal) de TEU ${ }^{16}$ interí amb propòsit de fer la tesi doctoral en dos o tres anys va fer augmentar el nivell dels sous més baixos i va facilitar l'acabament del pool, en esdevenir funcionaris.

\section{Reflexions finals (I)}

La geografia plantejada per Enric Lluch com a ciència social necessitava uns coneixements bàsics d'economia, història i sociologia, però també coneixements instrumentals de matemàtiques, estadística, cartografia o SIG, per poder fer front a una anàlisi global dels processos que es donaven al territori.

Enfront del discurs individual, en el col-lectiu de geògrafs i geògrafes de la $\mathrm{UAB}$ es va plantejar la discussió en grup dels continguts i dels enfocaments de cada assignatura en relació amb la realitat canviant de la societat, la qual cosa va comportar traslladar aquest plantejament de la docència a la recerca.

Aquest canvi va ser possible a causa de les relacions de la geografia que s'impartia a la UAB amb la d'altres països (França, Itàlia, Països Baixos, Portugal, Anglaterra i els EUA), que seguien uns plantejaments innovadors i que es va realitzar mitjançant estades del professorat, organització de seminaris, professorat visitant i traducció d'un nombre significatiu de publicacions.

Aquests nous coneixements varen posar-se en comú amb les experiències de nous enfocaments crítics a la història i en altres disciplines afins, juntament amb les noves aportacions pedagògiques i els nous objectius de recerca.

D'aquesta manera ha estat possible desenvolupar els coneixements teòrics de la geografia juntament amb la projecció aplicada en l'ordenament del territori i la gestió ambiental. La transversalitat dels ensenyaments geogràfics ha afavorit les aliances amb altres disciplines afins.

Els seminaris i les jornades de formació varen ajudar a consolidar aquests coneixements. La combinació entre un treball col.lectiu regular per a cada assignatura i una millora global dels estudis va permetre que es creés un grup cohesionat i amb objectius clars. La geografia, com a disciplina pràctica, va afavorir la generació d'infraestructures de docència i de recerca juntament amb el desenvolupament del treball de camp.

La contractació de professorat de diverses disciplines (economia, sociologia, demografia, enginyeria, etc.), juntament amb la importància de

16. Titular d'escola universitària, categoria que no exigeix tenir la tesi doctoral. En el Pla Nadal (1986-1991) es van anar concedint places de TEU interí durant tres anys, amb el compromís de dipositar la TdD en dos o tres anys. Se’n varen concedir nou a Geografia. 
les matèries tècniques, va ajudar a poder impartir aquesta nova docència $\mathrm{i}$ investigació amb els nous enfocaments crítics i amb el planejament territorial. El professorat de geografia va reforçar la seva competència mercès a aquestes relacions interdisciplinàries i a la formació en estudis i estades en altres països.

La creació de noves universitats durant la dècada de 1990 va afavorir que les característiques de la geografia que s'impartia a la UAB es reproduïssin en els altres centres d'ensenyament superior, com és el cas de Girona.

La cohesió del grup entorn del lideratge d'Enric Lluch i la consolidació institucional del professorat van permetre oferir estudis d'interès social $i$ acadèmic, com també la creació de grups de recerca, més endavant reconeguts com grups SGR (Suport a Grups de Recerca) per la Generalitat de Catalunya.

\section{Referències bibliogràfiques}

AlBet, Abel (2007). Enric Lluch i Martin: L'obra escrita. Edició a dura d'Abel Albet i Mas. Barcelona: Societat Catalana de Geografia, IEC.

Alegre, Pau (1988). Alternatives d'Ordenació Territorial: L'enfoc teòric. Tesi doctoral. Bellaterra: Servei de Publicacions de la UAB.

Beaujeau-Garnier, Jacqueline i Сhabot, Georges (1963). Traité de géographie urbaine. París: Armand Colin. Versió castellana: Geografía urbana. Barcelona: Vicens-Vives, 1970.

BRET, Bernard; Foucher, Michel; Giblin, Béatrice; Lacoste, Yves; GHirardi, Raymond (1977). Géographie Générale, physique et humaine. París: Fernand Nathan (traducció al castellà Geografía general, física y humana per Oikos-Tau, Vilassar de Mar, 1983).

BROOKFIELD, Harold (1975). Interdependent Development. Londres: Methuen.

Busquets, Jaume; CuAdRADO, Sergi; Rueda, Isabel; Tulla, Antoni F.; CaSADEVall, Robert i LLUSSÀ, Rafel (2015). «L'Associació de Geògrafs Professionals de Catalunya (AGPC): 25 anys al servei dels professionals de la geografia i del territori». Treballs de la Societat Catalana de Geografia, 80, 91-116.

CAstells, Manuel (1972). La question urbaine. París: François Maspero. Versió castellana: La cuestión urbana. Madrid: Siglo XXI, 1974. Versió anglesa: The urban question: A Marxist approach. Londres. Edward Arnold, 1977.

ChISHOLm, Michael D.I. (1962). Rural settlement and land use. Londres: Hutchinson University Library.

- (1965). Geography and Economy. Londres: Edward Arnold. Versió castellana: Geografia y Economía. Vilassar de Mar: Oikos-Tau, 1970.

Claval, Paul (1968). Régions, nations, grands espaces. París: Génin.

Colomer, Josep M. (1978). Els estudiants de Barcelona sota el franquisme. Barcelona: Curial.

DemmatTeIs, Giuseppe (1970). «Rivoluzione quantitativa» e nuova geografia. Torí: Università di Torino. Laboratorio de Geografia. Publicació editorial: Palermo: Floccovio, 1971.

- (2002). Progetto implicito: Il contributo della geografia umana alle scienze del territorio. Milà: Franco Angeli.

Derruau, Max (1976). Geographie Humaine. París: Armand Colin. Versió castellana: Geografí humana. Barcelona: Vicens-Vives, 1981. 
Dollfus, Olivier (1978). L'analyse géographique. París: Presses Universitaires de France. Versió castellana: El análisis geográfico. Vilassar de Mar: Oikos-Tau, 1978.

Estalella, Helena (1982). La propietat de la terra a les comarques gironines. Girona: Col-legi Universitari de Girona, 1984.

Estalella, Helena i Tulla, Antoni F. (1978). «El espacio como un producto social: El subdesarrollo del campo». V Coloquio de Geografía, Granada. Secretaría de Publicaciones de la Universidad de Granada, 303-306.

FERNÁNDEZ BueY, Francisco (2009). Por una universidad democràtica: Estudios sobre la universidad y los movimientos universitarios. Barcelona: Viejo Topo.

GAMBI, Lucio (1973). Una geografia per la storia. Torí: Einaudi.

GARCIA RAMON, Maria Dolors (1978). «The shaping of a rural Anarchist Landscape: Contributions from the Spanish Anarchist Theory». Antipode, 10-11 (3), 71-82.

- (1981). Métodos y conceptos en Geografía Rural. Vilassar de Mar: Oikos-Tau.

- (1985). Teoría y método en la Geografía Humana Anglosajona. Barcelona: Ariel.

GARnIER, Jean-Pierre (1973). Une ville, une révolution: La Havane. De l'urbain au politique. París: Anthropos.

Gourou, Pierre (1973). Pour une géographie humaine. París: Flammarion. Versió castellana: Introducción a la geografía humana. Madrid: Alianza Editorial, 1984.

Haggett, Peter (1965). Locational Analysis in Human Geography. Londres: Edward Arnold. Versió castellana: Análisis locacional en la geografía humana. Barcelona: Gustavo Gili, 1975.

Haggett, Peter; Cliff, Alan D. i Frey, Alan (1977). Locational analysis in human geography. 2 vol. Londres: Edward Arnold.

HarveY, David (1969). Explanation in Geography. Londres: Edward Arnold. Versió castellana: Teorias, leyes y modelos en geografía. Madrid: Alianza, 1983.

- (1973). Spatial Justice and the City. Londres: Edward Arnold. Versió castellana: Urbanismo y desigualdad social. Madrid: Siglo XXI, 1977.

IsARD, Walter (1960). Methods of Regional Analysis: An Introduction to Regional Science. Cambridge, MA: The MIT Press. Versió castellana: Métodos de Análisis Regional. Barcelona: Ariel.

KAYSER, Bernard (1972). «Les petites villes françaises» Revue de Géographie Alpine, 60 (2), 269-284.

Lacoste, Yves (1965). Geographie du Sous-developpement. París: PUF. Magellan. Versió castellana: Geografía del subdesarrollo. Barcelona: Ariel, 1988.

LEBEAU, René (1979). Les grands types de structures agraires dans le monde. París: Masson. Versió castellana: Grandes modelos de estructuras agrarias en el mundo. Barcelona: Vicens-Vives, 1983.

LefebVRe, Henri (1968). Le Droit à la ville. París: Éditions du Seuil. Versió castellana: El derecho a la ciudad. Madrid: Península, 1969.

LIPIETZ, Alain (1977). Le capital et son espace. París: François Maspero.

MASSEY, Doreen i MEEGAN, Richard (1982). The Anatomy of Job Loss. Londres: Methuen.

MONK, Janice i HANSON, Susan (1982). "On not excluding half of the human in Human Geography». The Professional Geography, 34 (1), 11-23.

PEET, Richard (1977). Radical Geography: Alternative viewpoints on contemporary social issues. Chicago: Maaroufa Press, Inc.

PerPiÑÁ GraU, Romà (1954). Corología: Teoría estructural y estructurante de la población en España (1900-1950). Madrid: Instituto de Economía Sancho de Moncada.

Postel-Vinay, Gilles (1974). La Rente foncière dans le capitalisme agricole. París: François Maspero. 
QUAINI, Massimo (1975). La costruzione della geografia umana. Florència: La Nuova Italia Editrize. Versió castellana: La construcción de la geografía humana. Vilassar de Mar: Oikos-Tau, 1981.

- (1978). Dopo la geografia. Farigliano (Cuneo): Espresso Strumenti.

Riera Figueras, Pilar (1988). Les àrees funcionals de Catalunya. Tesi doctoral. Bellaterra: Servei de Publicacions de la UAB.

Riquer, Borja de i Molinero, Carme (dirs.) (2018). L'audàcia del coneixement: 50 anys $U A B$. Bellaterra: Servei de Publicacions de la Universitat Autònoma de Barcelona.

SAUER, Carl O. (1956). "The Agency of man on the Earth». A: ThOMAS, W.L. (ed.). Man's role in changing the face of the Earth. Chicago: The University of Chicago Press, 49-69.

ShORT, John R. (1989). The Humane City. Oxford: Basil Blackwell Ltd.

SolÉ SABARís, Lluís (dir.) (1964). Geografia de Catalunya. Vol. II. Geografia comarcal. Barcelona: Aedos.

THRIFT, Nigel J. (1983). "On the determination of social action in space and time». Environment and Planning D: Society and Space, 1, 23-57.

Tulla, Antoni F. (1973). "Las cooperativas agrarias en el Pirineo: Una possible respuesta a las agriculturas marginales de alta montaña». Papers: Trabajos de Sociología, 1. Barcelona: Barral, 152-177.

- (1982, 1993). Procés de transformació agrària en àrees rurals de muntanya: Les explotacions lleteres com a motor de canvi. Barcelona: Institut Cartogràfic de Catalunya (tesi doctoral llegida el mes de gener de 1982).

ViCENS VIVES, Jaume (1950, 1981). Tratado General de Geopolítica: El factor geográfico y el proceso histórico. 3a ed. Barcelona: Vicens-Vives, 1981.

- (1954, 1962). Notícia de Catalunya. Barcelona: Vicens-Vives. Versió castellana ampliada, 1962.

Vila, Pau (1926). La Cerdanya. Barcelona: Barcino.

VILAR, Pierre (1962). La Catalogne dans l'Espagne moderne: Recherches sur les fondements économiques des structures nationales. París: SEVPEN. Versió catalana: Catalunya dins l'Espanya moderna. Barcelona: Edicions 62, 1966. 


\section{Annex I}

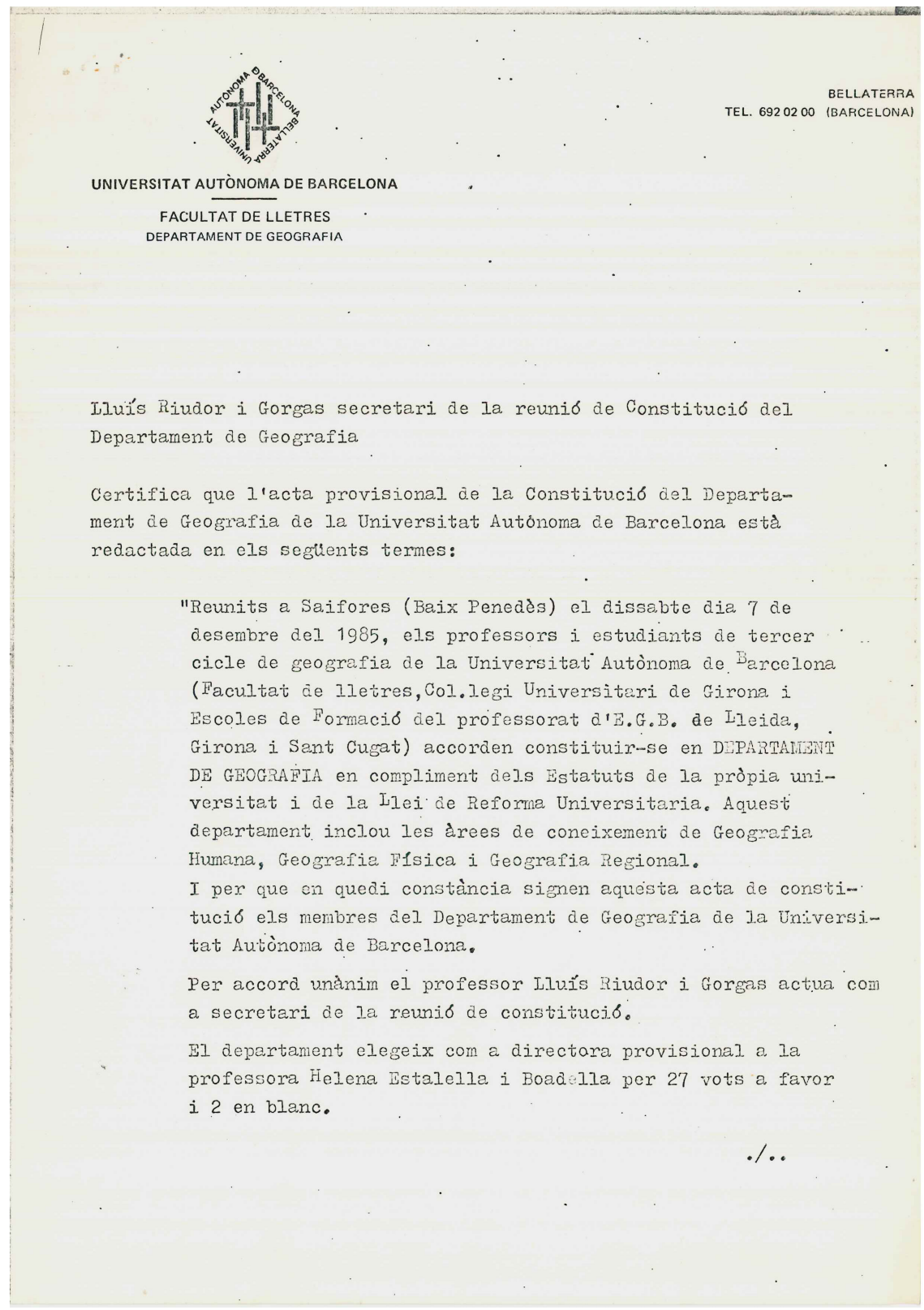




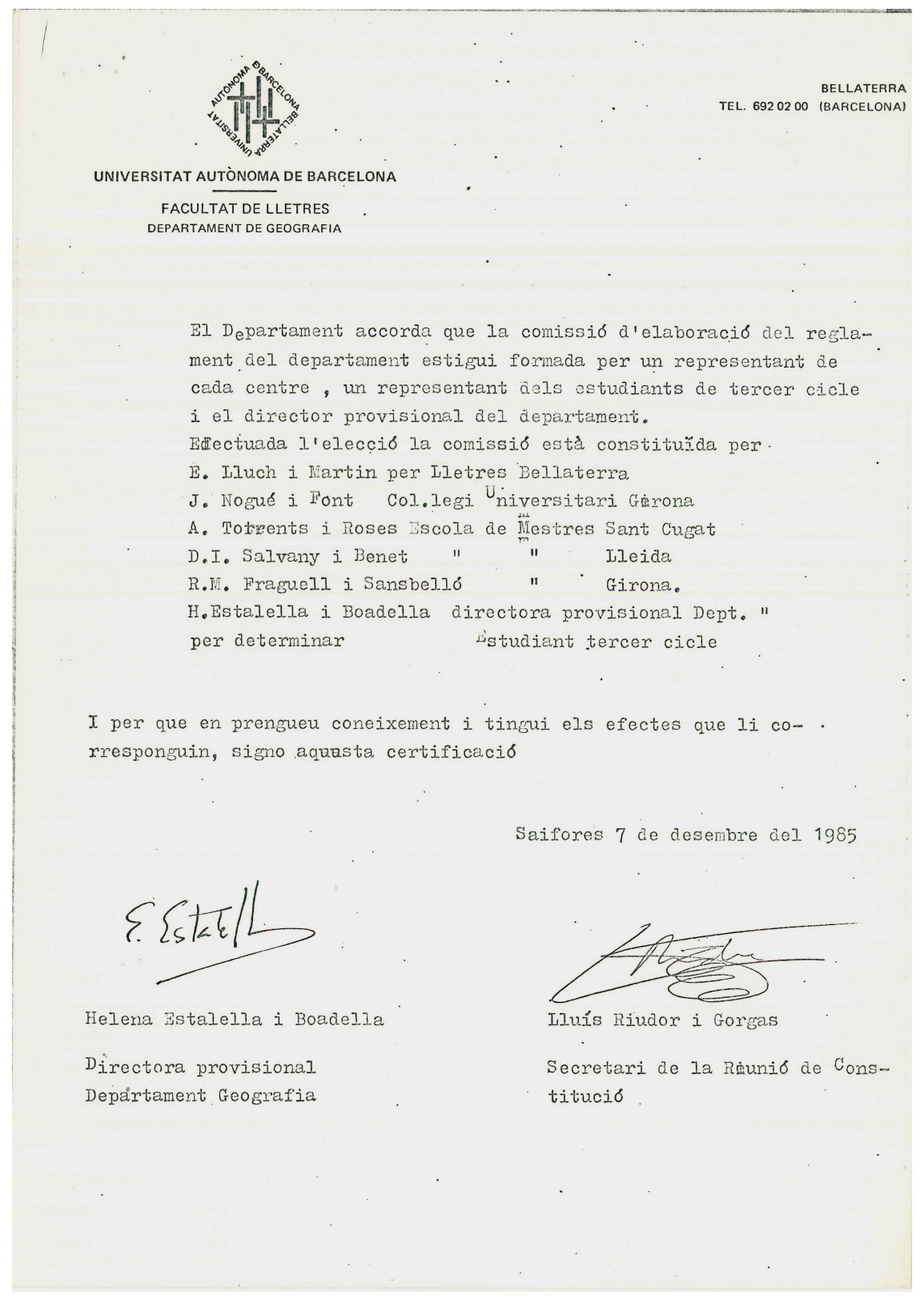




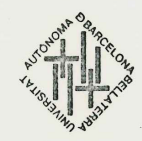

BELLATERRA

TEL. 6920200 (BARCELONA)

\section{UNIVERSITAT AUTÒNOMA DE BARCELONA}

FACULTAT DE LLETRES

DEPARTAMENT DE GEOGRAFIA

Professorat Departament de Geografia Universitat Autonoma de Barcelona

\section{Area de Geografia Huamena}

Alegre i ivadal, Pau

Ascon i Borras, Rosa

Col,laborador Fac. Ixclusiva

Blanco i Gutierrez, Ii.A. Cabre i Pla, Anna

$$
\text { . " }
$$

"

Corominas i Viñas, J.

Col.laborador Fac Exclusiva

Estalella i Boadella,H

Titular Fac.

Font i Serrano, Nuria

Encarregada curs

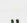

Fraguell i Sansbell6,R.In. Titular Escola

Garcia Ramon, M.D.

Catedratic Fac.

Gonzalo i Garcia,c.

Iluch i llartin, $\mathrm{E}$.

Nogué i Font, Joan

Titular Iscola

Titular Fac.

Pascuel de Sans, Angels

Priestley, Gerda

Fuig i Boix, Josep

Riera i pigueras, Pilar

Rividor $i$ Gorges, IJ].

Salvany i Benet, D.I.

Torrent i Roses, Angels

Tort i. Xavarria, $\mathrm{F}$.

" $"$

"

i

"

Col.1aborador Fac.

4 encarrecs

exclusiva

Tulla i Pujol, A. F.

"1

Titular Escola

"

"I

Encarregat curs 3 enc.

Titular Fac.

"

"1

"I

"

"

$n$

11

"

"

"

Villanueva i llargalef, M. Titular Esc.

Zumin i Tartari, Laura Col.laborador Fac. 


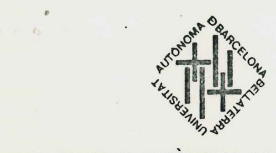

UNIVERSITAT AUTÒNOMA DE BARCELONA

FACULTAT DE LLETRES

DEPARTAMENT DE GEOGRAFIA

BELLATERRA

TEL. 6920200 (BARCELONA)

\section{Area de Geografia PÍsica}

Itazarico i Felix, M.P.

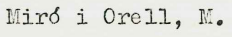

Sabf i Bonastre, J.

Xercavins $i$ Čomas, A

\section{Titular Escola}

Exclusiva

Titular Fac.

"1

. 11

II

i

11

\section{- Han demanat canvi d'area:}

Josefina Diaz i Piñen de Didactica de les Ciencies Socuials
- .
a Geografia

Josep Tortosa i Duran d'historia moderna i contemporanea a

a Geografia 
Annex Ila. Professorat de geografia o assimilat de la UAB als campus de Sant Cugat i Bellaterra (1969-1989)

\begin{tabular}{|c|c|c|c|c|}
\hline \multirow[b]{2}{*}{$\begin{array}{c}\text { CURS } \\
\text { (unitat organitzativa) }\end{array}$} & \multicolumn{3}{|c|}{ Incorporacions a la unitat organitzativa } & \multirow{2}{*}{$\begin{array}{l}\text { Assignatures } \\
\text { específiques } \\
\text { i aclariments }\end{array}$} \\
\hline & Bellaterra & Data d'alta & $\begin{array}{l}\text { Data de baixa fins } \\
\text { setembre de } 1990\end{array}$ & \\
\hline 1969-1970 & Enric Lluch Martin & Octubre 1969 & -- & Geografia \\
\hline \multirow{5}{*}{$\begin{array}{l}\text { (Departament de } \\
\text { Ciències Socials) }\end{array}$} & M. Dolors Garcia Ramon & Id. & -- & Geografia \\
\hline & Ricardo Moragas Moragas & Id. & Setembre 1970 & Sociologia \\
\hline & Jaume Lanaspa Gatnau & Id. & Setembre 1970 & Sociologia \\
\hline & Antoni Jutglar Bernaus & Id. & Setembre $1971^{1}$ & Història política \\
\hline & Jordi Sobrequés Callicó & Id. & Setembre $1971^{1}$ & Història de Catalunya \\
\hline \multirow{5}{*}{$\begin{array}{l}1970-1971 \\
\text { (Departament de } \\
\text { Ciències Socials) }\end{array}$} & Helena Estalella Boadella & Octubre 1970 & -- & Geografia \\
\hline & Laura Zumin Tartari & Id. & -- & Geografia \\
\hline & Jordi Borja Sebastiá & Id. & Octubre 1985 & Geografia \\
\hline & Juli Busquets Bragulat² & Id. & Octubre 1985 & Sociologia \\
\hline & Antoni F. Tulla Pujol ${ }^{3}$ & Id. & -- & Sociologia \\
\hline \multirow{8}{*}{$\begin{array}{l}\text { 1971-1972 } \\
\text { (Departament de } \\
\text { Ciències Socials) }\end{array}$} & Rosa Ascon Borras & Octubre 1971 & -- & Geografia \\
\hline & Pilar Benejam Arguimbau ${ }^{4}$ & Id. & Octubre 1985 & Didàctica de geogr. \\
\hline & Eugeni Giral Quintana ${ }^{5}$ & Id. & Setembre 1976 & Economia/Int. geogr. \\
\hline & Emili Gasch Grau ${ }^{6}$ & Id. & Setembre 1972 & Economia/Int. geogr. \\
\hline & Núria Moreu Huet & Id. & Setembre 1978 & Geografia \\
\hline & Gerda K. Priestley ${ }^{7}$ & id. & -- & Geografia/Cartogr. \\
\hline & Pilar Riera Figueras & Id. & -- & Geografia \\
\hline & Lluís Riudor Gorgas & Id. & -- & Geografia \\
\hline \multirow{6}{*}{$\begin{array}{l}1972-1973^{8} \\
\text { Divisió de Geografia } \\
\text { «corredor» }\end{array}$} & Àngels Pascual de Sans & Octubre 1972 & -- & Migracions i Geogr. \\
\hline & Maria Dolors Vila Pineda & Id. & Setembre 1974 & Cartografia \\
\hline & Maria Villanueva Margalef & Id. & -- & Geografia \\
\hline & Francesc Gallart Gallego & & Setembre 1974 & G. Física (Geòleg) \\
\hline & Fernando Manero Miguel $^{9}$ & Juny 1972 & Setembre 1973 & Geògraf \\
\hline & Mercedes Marín Ramos ${ }^{10}$ & -- & -- & Geografia Física \\
\hline \multirow[t]{2}{*}{$1973-1974$} & David Serrat Congost & Octubre 1973 & Setembre 1975 & G. Física (Geòleg) \\
\hline & Ernest Maragall Mira ${ }^{11}$ & & Setembre 1974 & Economia \\
\hline \multirow[t]{4}{*}{$1974-1975^{12}$} & Eusebio Garcia Manrique ${ }^{13}$ & Octubre 1974 & Setembre 1977 & Geografia \\
\hline & Jordi Vives Arumi & Id. & Setembre 1976 & Estadística \\
\hline & Enriqueta Fontquerni Ribó11 & Id. & Setembre 1979 & Economia \\
\hline & Àngels Torrents Roses & Id. & -- & Escola de Mestres \\
\hline \multirow[t]{4}{*}{$1975-1976$} & Carmen 0caña 0caña ${ }^{14}$ & Octubre 1975 & Setembre 1977 & Geografia \\
\hline & Pau Alegre Nadal & Id. & -- & Geografia/Cartogr. \\
\hline & Josep Sales Boluña11 & Id. & Setembre 1983 & Economia \\
\hline & M. Dolors Riba Lloret ${ }^{15}$ & Id. & Setembre 1978 & Estadística \\
\hline \multirow[t]{2}{*}{ 1976-1977 } & Josep Verd Crespí & Octubre 1976 & Setembre 1979 & Geografia Física \\
\hline & Carmen Gonzalo Garcia & Id. & -- & Escola de Mestres \\
\hline \multirow[t]{3}{*}{$1977-1978$} & Eugenio Burriel de Orueta ${ }^{16}$ & Octubre 1977 & Setembre 1981 & Geografia \\
\hline & Joan Biosca Torres ${ }^{15}$ & & Desembre 1978 & Estadística \\
\hline & Anna Cabré Pla ${ }^{17}$ & Id. & -- & Demografia \\
\hline \multirow[t]{3}{*}{ 1978-1979 } & Antoni Castells Duran ${ }^{11}$ & Octubre 1978 & Setembre 1985 & Economia \\
\hline & Guillem Sànchez Juliachs & Gener 1979 & Setembre 1979 & Estadística \\
\hline & Jaume Calvet & Octubre 1978 & Setembre 1979 & G. Física (Geòleg) \\
\hline
\end{tabular}


Annex lla. Professorat de geografia o assimilat de la UAB als campus de Sant Cugat i Bellaterra (1969-1989) (continuació)

\begin{tabular}{|c|c|c|c|c|}
\hline \multirow[b]{2}{*}{$\begin{array}{c}\text { CURS } \\
\text { (unitat organitzativa) }\end{array}$} & \multicolumn{3}{|c|}{ Incorporacions a la unitat organitzativa } & \multirow{2}{*}{$\begin{array}{l}\text { Assignatures } \\
\text { específiques } \\
\text { i aclariments }\end{array}$} \\
\hline & Bellaterra & Data d'alta & $\begin{array}{l}\text { Data de baixa fins } \\
\text { setembre de } 1990\end{array}$ & \\
\hline $1979-1980$ & $\begin{array}{l}\text { Muriel Casals Cotourier }{ }^{11} \\
\text { Joaquim Corominas Viñas } \\
\text { Manuel de Miró Orell }\end{array}$ & $\begin{array}{l}\text { Octubre } 1979 \\
\text { Id. } \\
\text { Id. }\end{array}$ & $\begin{array}{l}\text { Setembre } 1984 \\
-- \\
--\end{array}$ & $\begin{array}{l}\text { Economia } \\
\text { Estadística/Inform. } \\
\text { G. Física (Geòleg) }\end{array}$ \\
\hline $1980-1981$ & Joan Sabí Bonastre & Octubre 1980 & -- & Geografia Física \\
\hline $1981-1982$ & Josep Puig Boix & Octubre 1981 & -- & Estadística/Inform. \\
\hline 1983-1984 & Maite Cabeza Gutes ${ }^{11}$ & Octubre 1983 & Setembre 1984 & Economia \\
\hline 1984-1985 & Francesc Tort Chavarria & Octubre 1984. & Setembre 1985 & Sociologia \\
\hline $\begin{array}{l}\text { 1985-1986 } \\
\text { (Departament de } \\
\text { Geografia UAB) }\end{array}$ & $\begin{array}{l}\text { Francesca Antolín Fargas }{ }^{11} \\
\text { Josep Pujol Andreu }\end{array}$ & $\begin{array}{l}\text { Octubre } 1985 \\
\text { Id. }\end{array}$ & $\begin{array}{l}\text { Setembre } 1989 \\
\text { Setembre } 1989\end{array}$ & $\begin{array}{l}\text { Economia } \\
\text { Economia }\end{array}$ \\
\hline 1986-1987 & $\begin{array}{l}\text { Francesc Muñoz Pradas } \\
\text { Montserrat Solsona Pairo } \\
\text { David Guasch Torres }\end{array}$ & $\begin{array}{l}\text { Octubre } 1986 \\
\text { Id. } \\
\text { Id }\end{array}$ & $\begin{array}{l}-- \\
-- \\
--\end{array}$ & $\begin{array}{l}\text { Demografia } \\
\text { Demografia } \\
\text { Geografia }\end{array}$ \\
\hline 1987-1988 & $\begin{array}{l}\text { Purificació Alba Luque } \\
\text { Agustina Blanco Gutierrez } \\
\text { Margarida Castañer Vivas }{ }^{18}\end{array}$ & $\begin{array}{l}\text { Octubre } 1987 \\
\text { Id. } \\
\text { Id. }\end{array}$ & $\begin{array}{l}\text { Setembre } 1988 \\
\text { Setembre } 1988 \\
\text { Setembre } 1988\end{array}$ & $\begin{array}{l}\text { Geografia } \\
\text { Demografia } \\
\text { Geografia }\end{array}$ \\
\hline 1988-1989 & $\begin{array}{l}\text { Gemma Cànoves Valiente }{ }^{18} \\
\text { David Saurí Pujol } \\
\text { Oriol Nel·lo Colom }\end{array}$ & $\begin{array}{l}\text { Octubre } 1988 \\
\text { Id. } \\
\text { Id. }\end{array}$ & $\begin{array}{l}-- \\
-- \\
--\end{array}$ & $\begin{array}{l}\text { Geografia } \\
\text { Geografia } \\
\text { Geografia }\end{array}$ \\
\hline 1989-1990 & $\begin{array}{l}\text { Joan Nunes Alonso } \\
\text { Pilar Comes Solé } \\
\text { M. Cristina Guisande Allende }\end{array}$ & $\begin{array}{l}\text { Octubre } 1989 \\
\text { Id. } \\
\text { Id. }\end{array}$ & $\begin{array}{l}-- \\
-- \\
--\end{array}$ & $\begin{array}{l}\text { Geografia } \\
\text { Didàct. de CC.SS. } \\
\text { Demografia }\end{array}$ \\
\hline
\end{tabular}

Font: arxiu departament, anuaris Facultat de Lletres i de Filosofia i Lletres, arxius professorat.

Notes:

1. Passen al Departament d'Història.

2. En constituir-se els departaments LRU passa a formar part del de Sociologia, encara que manté una taula i arxius en el de Geografia.

3. Entra com a ajudant de sociologia i quan marxa amb una beca del patronat UAB al Geography Department at Bristol University (UK) passa a Geografia.

4. Passa al Departament de Didàctica de les Ciències Socials en constituir-se els departaments LRU;

5. S'ubica a la Facultat de Ciències de la Informació.

6. Professor de la Facultat d'Econòmiques que va impartir una introducció a la geografia a la Facultat de Ciències de la Informació.

7. Va demanar una excedència de 1975-1976 a 1977-1978 per maternitat.

8. Concurs públic a la UAB amb 200 places de professorat adjunt o catedràtic, inclosos alguns del departament.

9. Concurs guanyat el juny, amb assistència a cursos de formació, i renuncia el setembre.

10. Renuncia després de guanyar el concurs.

11. Professorat de la Facultat de Ciències Econòmiques que imparteix l'Economia al Departament.

12. Tot el professorat passa a encarregat de curs contractat, excepte el catedràtic i 3 adjuntes (M. D. Garcia Ramon, M. Villanueva i A.F. Tulla).

13. Primer catedràtic numerari, va ser elegit degà de la Facultat.

14. Adjunta numerària.

15. Departament de Psicologia.

16. Segon catedràtic numerari, va ser elegit degà de la Facultat.

17. Anna Cabré va estar el curs 1981-1982 a la UNAM (Universidad Nacional Autónoma de México).

18. Va guanyar una ajudantia a la Facultat de Lletres (Bellaterra) i l'any següent la va guanyar a Girona. La Gemma Cànoves va fer el camí invers. 
Annex Ilb. Professorat de geografia o assimilat de la UAB al Campus de Girona (1969-1989) ${ }^{1}$

\begin{tabular}{|c|c|c|c|c|}
\hline \multirow[b]{2}{*}{ CURS } & \multicolumn{3}{|c|}{ Incorporacions a la unitat organitzativa del Col·legi de Girona } & \multirow[b]{2}{*}{$\begin{array}{l}\text { Assignatures específiques } \\
\text { i aclariments }\end{array}$} \\
\hline & Girona & Data d'alta & $\begin{array}{l}\text { Data de baixa fins } \\
\text { setembre de } 1990\end{array}$ & \\
\hline $1969-1970$ & Montserrat Molí Frigola & Octubre 1969 & Setembre 1970 & Historiadora. Pràctiques Geogr. \\
\hline $1975-1976$ & Conxa Pla Torras & Octubre 1975 & Setembre 1981 & Economista \\
\hline 1976-1977 & $\begin{array}{l}\text { Agustí Xercavins Comas } \\
\text { Montserrat Terradas Batlle }\end{array}$ & $\begin{array}{l}\text { Octubre } 1976 \\
\text { Id. }\end{array}$ & Setembre 1983 & $\begin{array}{l}\text { Geografia Física } \\
\text { Geografia }\end{array}$ \\
\hline $1978-1979$ & Antoni Crespo & Octubre 1978 & Setembre 1981 & Estadística CCHH \\
\hline $1979-1980$ & $\begin{array}{l}\text { Ricard Masó Llunes } \\
\text { Rosa M. Fraguell Sansbello }\end{array}$ & $\begin{array}{l}\text { Octubre } 1979 \\
\text { Id. }\end{array}$ & $\begin{array}{l}\text { Setembre } 1983 \\
-\end{array}$ & $\begin{array}{l}\text { Cartografia } \\
\text { Geografia Esc. Mestres }\end{array}$ \\
\hline $1981-1982$ & Núria Font Serrano ${ }^{2}$ & Octubre 1981 & Setembre 1988 & Economia \\
\hline $1983-1984$ & $\begin{array}{l}\text { Joan Nogué Font }{ }^{3} \\
\text { Roser Batllori Obiols } \\
\text { Rosa Maria Medir Huerta }\end{array}$ & $\begin{array}{l}\text { Octubre } 1983 \\
\text { Id. } \\
\text { Id. }\end{array}$ & $\begin{array}{l}- \\
- \\
\text { Setembre } 1987\end{array}$ & $\begin{array}{l}\text { Cartografia/Geografia } \\
\text { Didàctica de les CCSS } \\
\text { G. Física Esc. Mestres }\end{array}$ \\
\hline 1986-1987 & Gemma Cànoves Valiente ${ }^{6}$ & Octubre 1986 & Setembre 1988 & Geografia \\
\hline 1987-1988 & Isabel Salamaña Serra & Octubre 1987 & - & Geografia \\
\hline 1988-1989 & $\begin{array}{l}\text { Margarida Castañer Vivas } \\
\text { Xavier Paunero Amigó } \\
\text { Anna M. Malvesí Bancells }\end{array}$ & $\begin{array}{l}\text { Octubre } 1988 \\
\text { Id. } \\
\text { Id. }\end{array}$ & $\begin{array}{l}- \\
- \\
\text { Febrer } 1989\end{array}$ & $\begin{array}{l}\text { Geografia } \\
\text { Economia/Geografia } \\
\text { Cobrir baixa geògraf }\end{array}$ \\
\hline
\end{tabular}

Font: arxiu departament, anuaris Facultat de Lletres i de Filosofia i Lletres, arxius professorat.

Notes:

1. El curs 1992-1993 es constitueix la Universitat de Girona que agrupa tots els centres de les universitats de Barcelona, Autònoma de Barcelona i Politècnica de Catalunya a les terres gironines.

2. Va substituir la Conxa Pla.

3. Va entrar per substituir en Ricard Masó fent cartografia.

4. Va substituir la Montserrat Terradas.

5. Figura a les memòries de recerca del departament com a professora associada de geografia física, però ben aviat va entrar a formar part del Departament de Didàctiques Específiques de l'Escola de Mestres de Girona.

6. Va estar dos cursos a Girona i després va guanyar una plaça d'ajudant a Bellaterra.

7. Primer va estar un any com a ajudanta a Bellaterra i després va guanyar la plaça a Girona. 
Annex Ilc. Professorat de geografia o assimilat de la UAB al Campus de Lleida (1969-1989) ${ }^{1}$

\begin{tabular}{|c|c|c|c|c|}
\hline \multirow[b]{2}{*}{ CURS } & \multicolumn{3}{|c|}{ Incorporacions a la unitat organitzativa de Lleida } & \multirow[b]{2}{*}{$\begin{array}{l}\text { Assignatures específiques } \\
\text { i aclariments }\end{array}$} \\
\hline & Lleida & Data d'alta & $\begin{array}{l}\text { Data de baixa fins } \\
\text { setembre de } 1990\end{array}$ & \\
\hline $\begin{array}{l}\text { 1972-1973 } \\
\text { Llicenciatura }\end{array}$ & Ana Maria Sainz & Octubre 1972 & Setembre 1974 & $\begin{array}{l}\text { Professora Geogr./Ha Institut } \\
\text { de Batxillerat }\end{array}$ \\
\hline $\begin{array}{l}\text { 1973-1974 } \\
\text { Llicenciatura }\end{array}$ & Ramon Morell Rosell & Octubre 1973 & Setembre 1974 & $\begin{array}{l}\text { Economista Cambra de } \\
\text { Comerç de Lleida }\end{array}$ \\
\hline $\begin{array}{l}\text { 1974-1975 } \\
\text { Escola de } \\
\text { Mestres }\end{array}$ & Divina Salvany Benet & Octubre 1974 & -- & Geografia \\
\hline $\begin{array}{l}\text { 1980-1981 } \\
\text { Escola de } \\
\text { Mestres }\end{array}$ & M.P. Mazarico Felix & Octubre 1980 & Setembre 1988 & Geografia Física \\
\hline $\begin{array}{l}\text { 1985-1986 } \\
\text { Escola de } \\
\text { Mestres }\end{array}$ & $\begin{array}{l}\text { Josefina Díaz Piñan² } \\
\text { Josep Tortosa Duran² }\end{array}$ & $\begin{array}{l}\text { Desembre } 1985 \\
\text { Id. }\end{array}$ & - & $\begin{array}{l}\text { Didàctica CCSS } \\
\text { Història }\end{array}$ \\
\hline $\begin{array}{l}1989-1990 \\
\text { Escola de } \\
\text { Mestres }\end{array}$ & Jordi Domingo Coll & Octubre 1989 & - & Geografia \\
\hline
\end{tabular}

Font: arxiu departament, anuaris Facultat de Lletres i de Filosofia i Lletres, arxius professorat.

Notes:

1. El curs 1992-1993 es constitueix la Universitat de Lleida que agrupa tots els centres de les universitats de Barcelona, Autònoma de Barcelona i Politècnica de Catalunya a les terres de Lleida.

2. Es varen adscriure al Departament de Geografia de la UAB d'acord amb el que permetia la LRU. 
Annex III. Cens a l'abril de 1992 dels cossos docents de geografia a les universitats de l'Estat espanyol

\begin{tabular}{|c|c|c|c|c|c|c|c|c|c|c|c|c|}
\hline \multirow{2}{*}{$\begin{array}{c}\text { Àrea } \\
\text { Univ./ Cossos }\end{array}$} & \multicolumn{3}{|c|}{ Anàlisi Geog. Regional $^{1}$} & \multicolumn{4}{|c|}{ Geografia Física } & \multicolumn{4}{|c|}{ Geografia Humana } & \multirow{2}{*}{$\begin{array}{l}\text { Total } \\
\text { Univ. }\end{array}$} \\
\hline & $\mathrm{CU}^{2}$ & TU & TEU & CU & TU & CEU & TEU & CU & TU & CEU & TEU & \\
\hline Alacant & 2 & 7 & & & 1 & & & 1 & 4 & 1 & 2 & 18 \\
\hline Alcalà & 1 & 1 & & & 1 & & & 1 & 2 & & & 6 \\
\hline Autònoma B. ${ }^{3}$ & & & & & 3 & & & 2 & 13 & $1^{4}$ & 6 & 25 \\
\hline Autònoma M. & 1 & 5 & 2 & 1 & 7 & 1 & 2 & 2 & 7 & 1 & & 29 \\
\hline Baleares & & 1 & & & & & & 2 & 3 & & 1 & 7 \\
\hline Cádiz & & 1 & & & & & & 1 & & & 2 & 4 \\
\hline Castilla L.-M. & & 1 & 2 & & & & 1 & 1 & 2 & & 2 & 9 \\
\hline C. Barcelona & 4 & 3 & 2 & 1 & 8 & & 1 & 4 & 10 & & 3 & 36 \\
\hline Complutense & 1 & 8 & & 1 & 3 & & & 5 & 16 & & 3 & 37 \\
\hline Cantabria & 2 & 3 & & & 2 & & 1 & & 2 & & & 10 \\
\hline Córdoba & & 1 & 1 & & & & & 1 & 1 & & 1 & 5 \\
\hline Extremadura & 2 & 4 & & & 1 & & & & & & & 7 \\
\hline Granada & 2 & 8 & 1 & 1 & 1 & & 1 & 1 & 6 & 1 & 2 & 24 \\
\hline La Laguna & 1 & 3 & & 1 & 4 & & 1 & 1 & 3 & & 1 & 15 \\
\hline Las Palmas GC & & & & & 1 & & 1 & & 1 & 1 & 3 & 7 \\
\hline León & & 1 & & & 1 & & 1 & 1 & 3 & & & 7 \\
\hline Málaga & & 3 & 1 & & & & & 1 & 3 & & 1 & 9 \\
\hline Murcia & & 4 & & 1 & 4 & & & 1 & 3 & & 1 & 14 \\
\hline UNED & 1 & 8 & & & & & & & 3 & & & 12 \\
\hline Oviedo & 1 & 10 & & & 1 & 1 & 3 & 1 & 2 & & 2 & 21 \\
\hline País Basc & 1 & 2 & & & 1 & 1 & & & 1 & & & 6 \\
\hline Públ. Navarra & & & & & & & & 1 & & & & 1 \\
\hline Salamanca & 1 & 3 & & & 1 & & & 1 & 1 & & & 7 \\
\hline Santiago & 1 & 4 & & & & & & 1 & 5 & & 1 & 12 \\
\hline Sevilla & 1 & 5 & & 1 & 3 & & 1 & 1 & 6 & & 5 & 23 \\
\hline València & 1 & 5 & 2 & 2 & 7 & & 1 & 2 & 5 & & & 25 \\
\hline Valladolid & & 2 & & 1 & 2 & & & 1 & 1 & & 3 & 10 \\
\hline Vigo & & & 1 & & & & & & & & & 1 \\
\hline Zaragoza & 2 & 4 & 1 & 1 & 5 & & & 2 & 4 & & 3 & 22 \\
\hline TOTAL & 25 & 97 & 13 & 11 & 57 & 3 & 14 & 35 & 107 & 5 & 42 & 409 \\
\hline
\end{tabular}

Font: Consejo de Universidades; Secretaría General. Madrid (censo abril 1992).

Notes:

1. No hi havia CEU d'AGR en aquest any.

2. CU (catedràtic d'universitat), TU (professor titular d'universitat), CEU (catedràtic d'escola universitària) i TEU (professor titular d'escola universitària).

3. No hi va haver professorat de l'àrea d'anàlisi regional a la UAB fins l'any 1995.

4. Correspon a la Pilar Benejam, CEU en l'àrea de Didàctica de les Ciències Socials.

Professorat UAB: Manuel de Miró, Joan Sabí, i Agustí Xercavins (TU GF); M. Dolors Garcia Ramon i Antoni F. Tulla (CU GH); Pau Alegre, Rosa Ascon, Anna Cabré, Gemma Cànoves, Helena Estalella, Francesc Muñoz Pradas, Joan Nogué, Àngels Pascual, Gerda K. Priestley, Pilar Riera, Lluís Riudor, David Saurí i Montserrat Solsona (TU GH); Jordi Domingo, M. Rosa Fraguell, M. Carmen Gonzalo, Divina Salvany, Àngels Torrents i Maria Villanueva (TEU GH); Pilar Benejam (CEU Didàctica de les Ciències Socials). 
Annex IV. Becaris (personal investigador en formació de programes oficials)

\begin{tabular}{|c|c|c|c|}
\hline Any natural & Becari/a & Director/a & Institució \\
\hline 1980 & Joan Nogué Font & M. Dolors Garcia Ramon & FPI - MEC ${ }^{1}$ \\
\hline 1982 & Xavier Mateu Llevadot & M. Dolors Garcia Ramon & FPI - MEC ${ }^{1}$ \\
\hline 1983 & Àngela Garcia Marcè & M. Dolors Garcia Ramon & $\mathrm{FPI}-\mathrm{MEC}^{1}$ \\
\hline 1984 & Abel Albet Mas & M. Dolors Garcia Ramon & $\mathrm{FPI}-\mathrm{MEC}^{1}$ \\
\hline 1985 & Mireia Belil Boladeras & M. Dolors Garcia Ramon & FPI - MEC ${ }^{1}$ \\
\hline 1986 & $\begin{array}{l}\text { Joan Nunes Alonso } \\
\text { Isabel Clos Costa }\end{array}$ & $\begin{array}{l}\text { Antoni F. Tulla Pujol } \\
\text { M. Dolors Garcia Ramon }\end{array}$ & $\begin{array}{l}\mathrm{FPI}-\mathrm{MEC}^{1} \\
\mathrm{IEMB}^{2}\end{array}$ \\
\hline 1987 & $\begin{array}{l}\text { Alex Tarroja Coscuela } \\
\text { Antoni Durà Guimerà } \\
\text { Carme Miralles Guasch }\end{array}$ & $\begin{array}{l}\text { M. Dolors Garcia Ramon } \\
\text { M. Dolors Garcia Ramon } \\
\text { Antoni F. Tulla Pujol }\end{array}$ & $\begin{array}{l}\text { FPI - MEC }{ }^{1} \text { Conv. Extra. } \\
\text { FPI - MEC }{ }^{1} \text { Conv. Extra. } \\
\text { FPI - MEC }{ }^{1} \text { Conv. Extra. }\end{array}$ \\
\hline 1989 & $\begin{array}{l}\text { Núria Valdovinos Perdices } \\
\text { Joan Manuel Soriano Lopez } \\
\text { Enric Rodelles Parès }\end{array}$ & $\begin{array}{l}\text { M. Dolors Garcia Ramon } \\
\text { Manuel de Miró i Orell } \\
\text { Antoni F. Tulla Pujol }\end{array}$ & $\begin{array}{l}\mathrm{FPI}-\mathrm{MEC}^{1} \\
\mathrm{UAB} 1 \mathrm{a} \text { conv. beques } \\
\mathrm{FPI}-\mathrm{ME}^{\mathrm{C}} 1\end{array}$ \\
\hline 1990 & $\begin{array}{l}\text { Mireia Baylina Ferré } \\
\text { Josefina Lladó Font }\end{array}$ & $\begin{array}{l}\text { M. Dolors Garcia Ramon } \\
\text { Antoni F. Tulla }\end{array}$ & $\begin{array}{l}\mathrm{FPI}-\mathrm{MEC}^{1} \\
\mathrm{FPI}-\mathrm{MEC}^{1}\end{array}$ \\
\hline
\end{tabular}

Font: arxiu departament, currículum vitae interessats i arxius professorat.

Notes:

1. Plan de Formación de Personal Investigador del Ministerio de Educación y Ciencia.

2. beques de l'Institut d'Estudis Metropolitans de Barcelona per a dos anys renovables. Es concedien amb convocatòria pública a un nombre limitat de doctorands dels departaments de la UAB que participaven al IEMB. 
Annex V. Governança a Geografia. Responsables acadèmics i de gestió

\begin{tabular}{|c|c|c|c|c|}
\hline \multirow[b]{2}{*}{$\begin{array}{c}\text { Curs } \\
\text { Acadèmic }\end{array}$} & \multicolumn{2}{|c|}{ Responsables elegits } & \multirow[b]{2}{*}{ Càrrec i entitat departamental } & \multirow[b]{2}{*}{$\begin{array}{l}\text { Gestió o Administració } \\
\text { Departament }\end{array}$} \\
\hline & $\begin{array}{l}\text { Coordinador/a } \\
\text { Director/a }{ }^{1}\end{array}$ & $\begin{array}{l}\text { Sotscoordinador/a } \\
\text { Secretari/a Acad. }\end{array}$ & & \\
\hline 1969-1970 & Antoni Jutglar & $\begin{array}{l}\text { Enric Lluch (1r qtr.) } \\
\text { M. Dolors Garcia (2n) }\end{array}$ & $\begin{array}{l}\text { Coordinador del Departament } \\
\text { Ciències Socials (Fac. Lletres) }\end{array}$ & \\
\hline $1970-1971$ & Antoni Jutglar & $\begin{array}{l}\text { Enric Lluch (1r qtr.) } \\
\text { M. Dolors Garcia (2n) }\end{array}$ & $\begin{array}{l}\text { Coordinador del Departament } \\
\text { Ciències Socials (Fac. Lletres) }\end{array}$ & \\
\hline 1971-1972 & Enric Lluch & $\begin{array}{l}\text { M. Dolors Garcia } \\
\text { Helena Estalella }\end{array}$ & $\begin{array}{l}\text { Coordinador del Departament } \\
\text { Ciències Socials (Fac. Lletres) }\end{array}$ & \\
\hline $1972-1973$ & Enric Lluch & $\begin{array}{l}\text { M. Dolors Garcia } \\
\text { Helena Estalella }\end{array}$ & $\begin{array}{l}\text { Coordinador Divisió de Geografia } \\
\text { (Facultat de Lletres) }\end{array}$ & \\
\hline 1973-1974 & Enric Lluch & $\begin{array}{l}\text { M. Dolors Garcia } \\
\text { Helena Estalella }\end{array}$ & $\begin{array}{l}\text { Coordinador Divisió de Geografia } \\
\text { Facultat de Lletres) }\end{array}$ & \\
\hline 1974-1975 & Enric Lluch & $\begin{array}{l}\text { M. Dolors Garcia } \\
\text { Helena Estalella }\end{array}$ & Coordinadora Secció Geografia & \\
\hline $1975-1976$ & M. Dolors Garcia & $\begin{array}{l}\text { Carmen Ocaña / } \\
\text { Juli Busquets }\end{array}$ & Coordinadora Secció Geografia & \\
\hline $1976-1977$ & M. Dolors Garcia & & Coordinadora Secció Geografia & \\
\hline 1977-1978 & M. Dolors Garcia & & Coordinadora Secció Geografia & \\
\hline 1978-1979 & Rosa Ascon & & Coordinadora Secció Geografia & Anna Solà2 \\
\hline $1979-1980$ & Rosa Ascon & & Coordinadora Secció Geografia & Anna Solà \\
\hline 1980-1981 & Pilar Riera & & Coordinadora Secció Geografia & Anna Solà \\
\hline 1981-1982 & Pilar Riera & & Coordinadora Secció Geografia & \\
\hline 1982-1983 & Antoni F. Tulla & & Coordinador Secció Geografia & \\
\hline 1983-1984 & Helena Estalella & & Coordinadora Sec. Geografia & \\
\hline 1984-1985 & Helena Estalella & Lluís Riudor & Directora Dept. Geografia UAB. & \\
\hline 1985-1986 & Helena Estalella & Lluís Riudor & Directora Dept. Geografia UAB. & Eva Molins $^{3}$ \\
\hline $1986-1987$ & Antoni F. Tulla & Àngels Torrents & Director Dept. Geografia UAB & $\begin{array}{l}\text { Susanna Segura }{ }^{4} \\
\text { Carmen Franco }{ }^{5}\end{array}$ \\
\hline 1987-1988 & Antoni F. Tulla & Àngels Torrents & Director Dept. Geografia UAB & M. Dolors Ortiz \\
\hline 1988-1989 & Antoni F. Tulla & Gerda K. Priestley & Director Dept. Geografia UAB & M. Dolors Ortiz \\
\hline 1989-1990 & Gerda K. Priestley & Lluís Riudor & Director Dept. Geografia UAB & M. Izquierdo \\
\hline
\end{tabular}

Font: arxiu departament i arxius professorat.

Notes:

1. Des de 1984-1985 el departament es únic per a tota la UAB, incloent el professorat de tots els centres.

2. Administrativa de la Secretaria de la Facultat de Lletres que treballava al IUET-Geografia per les tardes.

3. Atenia temes del Departament de Geografia des de la Secretaria de la Facultat de Filosofia i Lletres.

4. Compartia dedicació entre els departaments d'Art i de Geografia.

5. Compartia dedicació entre els departaments d'Antropologia i Prehistòria i el de Geografia. 